Article

\title{
Comparison of the Reactivity and Structures for the Neutral and Cationic Bis(imino)pyridyl Iron and Cobalt Species by DFT Calculations
}

\author{
Zilong $\mathrm{Li}^{1,2} \mathbb{D}$, Yanping Ma ${ }^{1, * \mathbb{D}}$ and Wen-Hua Sun ${ }^{1,2,3, * \mathbb{D}}$ \\ 1 Key Laboratory of Engineering Plastics and Beijing National Laboratory for Molecular Sciences, \\ Institute of Chemistry, Chinese Academy of Sciences, Beijing 100190, China; lizilong@iccas.ac.cn \\ 2 CAS Research/Education Center for Excellence in Molecular Sciences, University of Chinese \\ Academy of Sciences, Beijing 100049, China \\ 3 State Key Laboratory for Oxo Synthesis and Selective Oxidation, Lanzhou Institute of Chemical Physics, \\ Chinese Academy of Sciences, Lanzhou 730000, China \\ * Correspondence: myanping@iccas.ac.cn (Y.M.); whsun@iccas.ac.cn (W.-H.S.); \\ Tel.: +86-10-6255-7955 (Y.M. \& W.-H.S.)
}

Received: 9 November 2020; Accepted: 29 November 2020; Published: 30 November 2020

\begin{abstract}
Density Functional Theory (DFT) method was adopted to investigate and compare the reaction mechanisms of ethylene polymerization catalyzed by neutral, cationic bis(imino)pyridyl (PDI) iron and cobalt derivatives. The electronic structure and the oxidation states of the metal center and the PDI ligand were analyzed by taking spin states, natural bond orbital (NBO) charge distribution, etc. into consideration, revealing that the reactivity is closely related to the valence electron numbers instead of the charge numbers. The neutral $\mathrm{Co}(0)$ had the lowest reactivity as it possessed the most electrons. During the formation of the cationic $\mathrm{Co}(+) / \mathrm{Fe}(+)$, one electron was mainly lost from PDI ligand rather than the metal center while the metal center maintained +II valence state through the process. Moreover, a special unsymmetrically bidentate $N^{\wedge} N$ coordination manner was found to provide the deficient metal surroundings with 14e, which may initiate the reactivity of some unsymmetrical species with rich electrons. Finally, an anion $\left[\mathrm{AlMe}_{4}\right]^{-}$participating process was proposed to explain the presence of the experimentally observed $\mathrm{LCo}(+) \mathrm{B}\left(\mathrm{C}_{2} \mathrm{H}_{4}\right)$. A special intermediate, $\mathrm{Co}(+) \mathrm{B}\left(\mathrm{C}_{2} \mathrm{H}_{4}\right)\left[\mathrm{AlMe}_{4}\right]^{-}$with $\mathrm{Co}$ in $+\mathrm{I}$ and absence of $\mathrm{Co}-\mathrm{C} \sigma$ bond, was obtained. These calculation results may provide fundamental information for further understanding and designing the ethylene polymerization catalysts.
\end{abstract}

Keywords: density functional theory; ethylene polymerization; 2,6-bis(imino)pyridyl complexes; reaction mechanism

\section{Introduction}

Much attention was focused on late transition metal complexes by researchers and engineers since Brookhart's and Gibson's research groups independently found that bis(imino)pyridine cobalt and iron complexes had high activities toward ethylene polymerization in 1998 [1,2]. Against this backdrop, the late transition metal complexes have made tremendous progress on ethylene polymerization by modifying the catalyst structures [3-10]. The introduction of a carbocyclic ring to the pyridine backbone [11-15] and the variation of substitution pattern in the $\mathrm{N}$-aryl groups [16-25] were found as effective ways to improve the catalytic performance. Numerous studies focusing on the relationship between catalyst structure and their catalytic activity have gradually been reported [26-37].

Spectroscopic techniques such as Electron Paramagnetic Resonance (EPR) and Nuclear Magnetic Resonance (NMR) were developed to help understand the nature of the active species in details [26-34]. 
Gibson et al. revealed that the iron centers in bis(imino)pyridyl iron(II) pre-catalysts( $\left(\mathrm{LFeCl}_{2}\right)$ were oxidized upon treatment with methylaluminoxane (MAO) to provide a $\mathrm{Fe}(\mathrm{III})$ active species $(\mathrm{LFe})$ [26]. In contrast, for the cobalt catalytic systems [27-29], the (iPr PDI) $\mathrm{Co}(\mathrm{II}) \mathrm{Cl}_{2}$ ( ${ }^{\mathrm{iPr} P D I}=$ (1E,1'E)-1,1'-(pyridine-2,6-diyl)bis(N-(2,6-diisopropylphenyl)ethan-1 -imine)) was firstly reduced to $\left({ }^{\mathrm{iPr}} \mathrm{PDI}\right) \mathrm{Co}(\mathrm{I}) \mathrm{Cl}$ by an alkylating agent $(\mathrm{MAO})$, then $\mathrm{Co}(\mathrm{I})$ alkyl species $\left(\mathrm{LCoCH}_{3}\right)$ was obtained. Talsi and coworkers [30-32] remarked the catalytic behavior of the bis(imino)pyridine iron and cobalt dihalide precatalyst upon addition of $\mathrm{MAO}$ or $\mathrm{AlMe}_{3}$, demonstrating the different types of active sites precursors present in different catalytic systems. Erker and colleagues [33] found that in the $\left({ }^{\mathrm{Ar}} \mathrm{PDI}\right) \mathrm{CoCH}_{3} / \mathrm{Li}\left[\mathrm{B}\left(\mathrm{C}_{6} \mathrm{~F}_{5}\right)_{4}\right] /$ ethylene system $\left({ }^{\mathrm{Ar}} \mathrm{PDI}=\left[\mathrm{bis}\left(\mathrm{N}\right.\right.\right.$-aryliminoethyl $\left.-\mathrm{kN}, \mathrm{N}^{\prime}\right)$ pyridine- $\left.\left.\mathrm{kN}\right]\right)$, $\mathrm{Li}^{+}$ions may interact with the "arms" of chelated donor ligands forming a reactive cationic reactant on the open coordination site. According to Talsi's results [34], the interaction of $\mathrm{L}^{3 \mathrm{Me}} \mathrm{Co}(\mathrm{II}) \mathrm{Cl}_{2}$ and $\mathrm{AlMe}_{3}$ at $-10{ }^{\circ} \mathrm{C}$ reduced cobalt (II) $\left(\mathrm{L}^{3 \mathrm{Me}} \mathrm{Co}(\mathrm{II}) \mathrm{Cl}_{2}\right)$ into a cobalt (I) complex $\left(\mathrm{L}^{3 \mathrm{Me}} \mathrm{Co}(\mathrm{II})(\mu-\mathrm{Me})(\mu-\mathrm{Cl}) \mathrm{AlMe}_{2}\right)$. Furthermore, in the presence of ethylene, newly formed complexes, such as (iPr PDI) $\mathrm{Co}(\mathrm{I}) \mathrm{C}_{2} \mathrm{H}_{4}{ }^{+}$, were also observed. However, up to now, the nature of the active species and the reaction mechanism of this special PDI-based iron or cobalt species were still in dispute.

In addition to experimental researches on the catalytic mechanism of the cobalt and iron catalysts based on a PDI backbone, many studies on theoretical calculations that overlay the mechanism were also reported [35-37]. In 1999, Gibson et al. [38] performed full ab initial computations on the bis(imino)pyridyl iron catalytic system for ethylene polymerization, and identified the key structure of ( $\left.{ }^{\mathrm{Ar}} \mathrm{PDI}\right) \mathrm{Fe}(\mathrm{II}) \mathrm{CH}_{3} \mathrm{C}_{2} \mathrm{H}_{4}$ as the product of the first monomer insertion into the cationic alkyl using the BP86 functionals. While just the singlet multiplicities was considered during calculation, this was proved to not be accurately described [39]. Later, Morokuma etc. theoretically investigated the mechanisms of chain propagation and $\beta$-hydride transfer (BHT) by considering three potential energy surfaces of the catalyst model, in which two cationic bis(imino)pyridyl-Fe(II) systems were explored with different steric effect [40]. They found that the BHT pathway could be suppressed by increasing the steric bulk and the chain propagation took place mainly on quintet or triplet surfaces. In order to explore the effect of cocatalyst in the catalytic process, Burin and coworkers [41] chose different additives including $(\mathrm{AlMeO})_{6}\left(\mathrm{AlMe}_{3}\right),(\mathrm{PhOAlMe})_{2}$ and TMA and calculated the activation and termination process of ethylene polymerization catalyzed by bis(imino)pyridyl iron catalysts using the unrestricted M06 functional. Altogether, the "alkyl-free" theory of polymerization catalyzed by bis(imino)pyridyl cobalt and polymerization mechanism have not been finalized and further researches are still necessary.

The reactivity differed due to the different charge or spin states of the active center. Herein, we used Density Functional Theory (DFT) to investigate and compare the reactivities of the cationic ( $\left.{ }^{\mathrm{Ar} P D I}\right) \mathrm{MCH}_{3}{ }^{+}$and neutral ( $\left.{ }^{\mathrm{Ar}} \mathrm{PDI}\right) \mathrm{MCH}_{3}\left(\mathrm{Ar}=2,6-\mathrm{Me}_{2} \mathrm{Ph}, \mathrm{M}=\mathrm{Fe}, \mathrm{Co}\right)$ of the iron and cobalt active species for the ethylene polymerization. Due to the limitation of the DFT calculations, just the following reaction processes were investigated: the first and second ethylene coordination and insertion, $\beta$-hydrogen transfer (BHT) to monomer and $\beta$-hydrogen elimination (BHE) reaction. Further, two kinds of spin states were considered. The differences of the electronic properties such as the NBO charge distribution, valence electron number and oxidation states and so on between the neutral and cationic iron or cobalt species were studied in detail. Moreover, in the case of the cobalt complex, a new reaction mechanism involving the cocatalyst ions $\left(\mathrm{AlMe}_{4}{ }^{-}\right)$was also simply analyzed.

\section{Results and Discussion}

To gain insight into the nature of the active species formed upon treatment of the corresponding metal dihalide complexes with MAO, various alkyl species based on bis(imino)pyridyl iron and cobalt complexes have been isolated in the experiments [2,27,42]. However, the activities and structures of the isolated species are related to the methodologies and additives which the researchers used during their alkylation synthesis. That means the actual electronic structures of the active centers varies in the charge distribution, spin states and the oxidation levels. Since the $\mathrm{LMCH}_{3}\left(\mathrm{M}=\mathrm{Fe}\right.$ and $\left.\mathrm{Co}, \mathrm{L}={ }^{\mathrm{Ar} P D I}\right)$ species 
are always considered as the initiated species towards ethylene polymerization, we select it as the model to explore the comparison between the iron and cobalt species by considering their neutral and cationic structures with different spin states. As shown in Scheme 1, the following reaction process are studied: the first coordination of the ethylene (Coord I), first insertion (Ins I), the second coordination (Coord II), second insertion (Ins II), $\beta$-hydrogen transfer (BHT) and $\beta$-hydrogen elimination (BHE). Comparison of energy curves (such as ethylene insertion and $\beta$-hydrogen transfer) demonstrated that there are some differences between the behavior of iron and cobalt complexes in polymerization, and also the spin states. The energy interval between the energy level of $\pi$-complex and sum of ethylene and catalyst energies could give the monomer coordination energy. Thus, the bond order of the special $\mathrm{LCoCH}_{3}$ and $\mathrm{LCoCH}_{3}-\mathrm{C}_{2} \mathrm{H}_{4}$ (2) and orbitals of the reaction intermediates were analyzed. Additionally, the charge distribution of the system and the oxidation state for the PDI ligand were discussed. Finally, the effect of cocatalyst ions on the ethylene reaction process by cobalt system was also considered and compared.

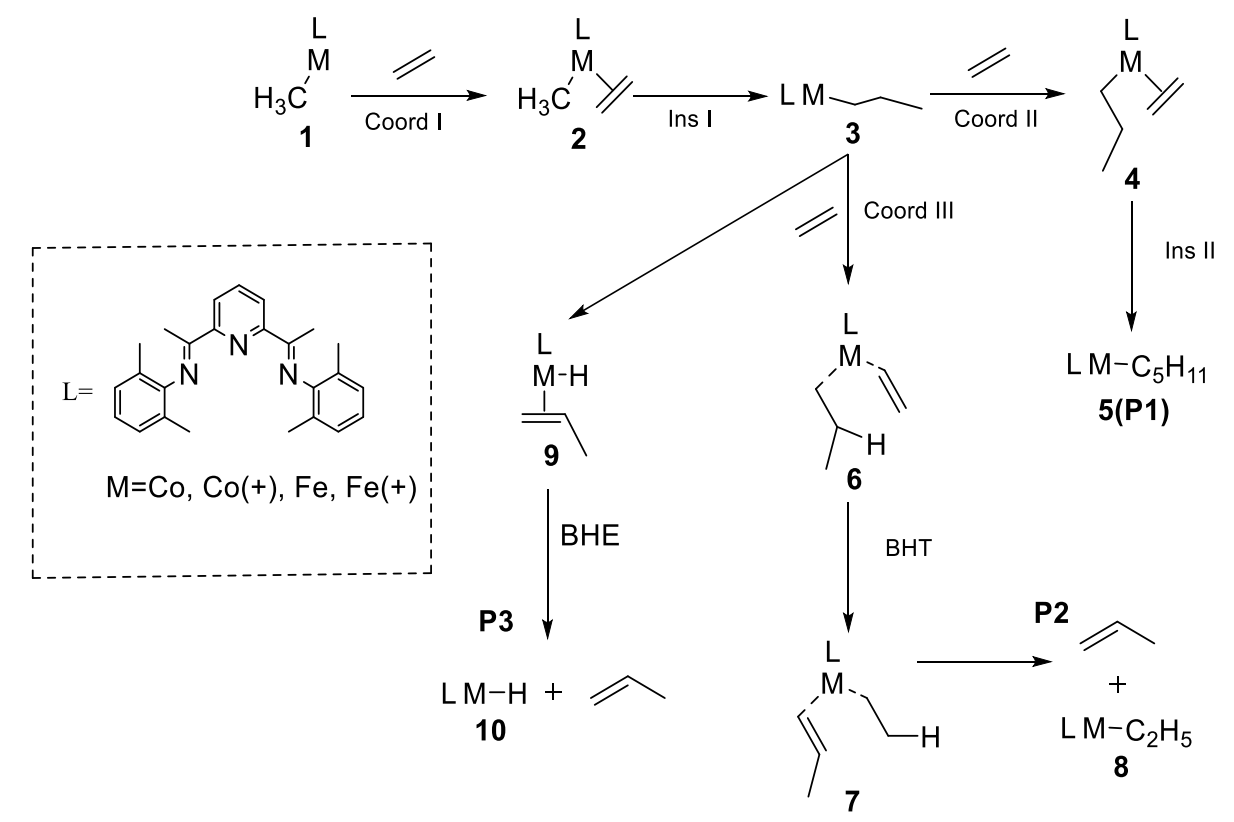

Scheme 1. The reaction pathway of ethylene polymerization catalyzed by $\mathrm{LMCH}_{3}(\mathrm{M}=\mathrm{Fe}$ and Co) species.

\subsection{Energy Profiles and Structures}

For clear description, the symbol ${ }^{\mathrm{s}} \mathbf{M}(q)-i$ was used to represent the intermediates in Scheme 1, where the ' $M$ ' could be the iron or cobalt metals, the ' $s$ ' is the spin quantum number, ' $q$ ' denotes charges and the ' $i$ ' corresponds to the intermediates in Scheme 1. For example, the initiated $\mathrm{LCoCH}_{3}$ will be ${ }^{1} \mathbf{C o}(\mathbf{0})-\mathbf{1}$ when it is neutral in the triplet.

\subsubsection{Energy Profiles and Structures of the Neutral $\mathrm{LCoCH}_{3}$ System}

Figure 1 shows the relative zero-point energy profile of the corresponding reaction in Scheme 1 for the neutral cobalt species, ${ }^{s} \mathbf{C o}(\mathbf{0})$. The optimized structures of all the points in Figure 1 are listed in Figures S1 and S2. The energies of the reactants: ${ }^{1} \mathbf{C o}(0)-1+\mathrm{C}_{2} \mathrm{H}_{4}$ were taking as the starting point, as the triplet ${ }^{1} \mathbf{C o}(0)-1$ has lower energy than the singlet ${ }^{0} \mathbf{C o}(0)-1$. Although both the singlet and triplet states were considered, the energies of most of the intermediates and transition state (TS) structures in triplet state ${ }^{1} \mathbf{C o}(\mathbf{0})$ are lower than the corresponding singlet ${ }^{0} \mathbf{C o}(\mathbf{0})$. The diffidence is $13.5 \sim 15.9 \mathrm{kcal} / \mathrm{mol}$ for the intermediates and $3.2 \sim 8.9 \mathrm{kcal} / \mathrm{mol}$ for the TS states. Although the energy differences between ${ }^{0} \mathbf{C o}(\mathbf{0})-\mathbf{1}$ and triplet ${ }^{1} \mathbf{C o}(0)-\mathbf{1}\left(\mathbf{1}^{\prime}\right.$ in Figure 1$)$ is not much, it seems that the behavior of neutral cobalt species tend to be in high spin states instead of the low spin state. However, the BHE process is a 
bit different. The transition state Co(0)-TS3/9 for the hydrogen transferred to the cobalt metal center, is lower in energy for its singlet state than triplet state. Thus, spin crossover behavior exists in the BHE process of the neutral cobalt alkyl complexes. This phenomenon has been reported by Holland in his special concentration on the BHE process [43].

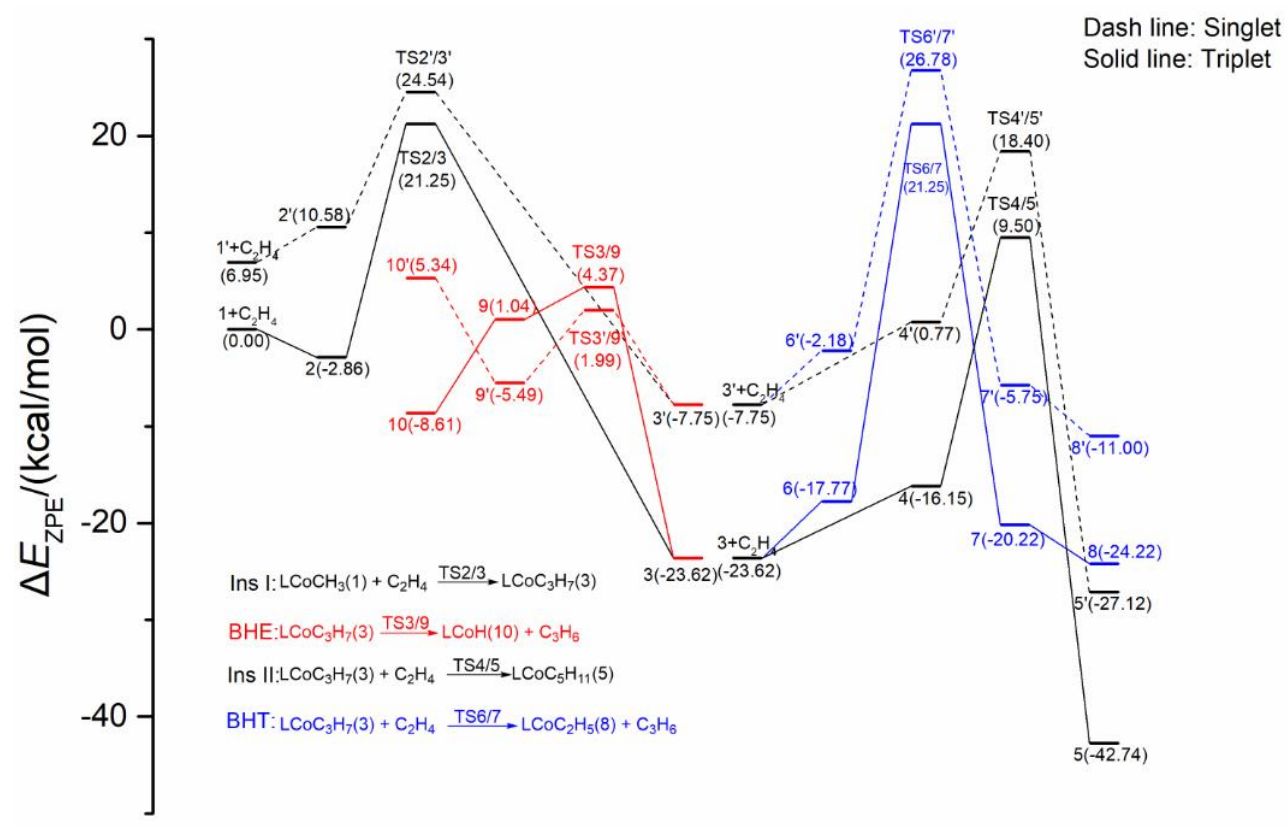

Figure 1. Energy profiles (kcal/mol) for the first and second ethylene coordination and insertion (black), $\beta-\mathrm{H}$ transfer (BHT, in blue) and $\beta-\mathrm{H}$ elimination (BHE, in red) catalyzed by the neutral cobalt complex in singlet (dash line) and triplet (solid line) spin states. The energies are relative zero-point energies with respect to the reactants: $\mathrm{LCoCH}_{3}(\mathbf{1})$ (triplet state) and $\mathrm{C}_{2} \mathrm{H}_{4}$. The number $\boldsymbol{n}$ corresponds to $\mathrm{Co}(\mathbf{0})-\boldsymbol{n}$, the TS $m / n$ refers to the transition state between the two intermediates $\operatorname{Co}(0)-m$ and $\operatorname{Co}(0)-n$. The $\boldsymbol{n}^{\prime}$ was used to distinguish structures between the two spin states, as is the same in the following Figures.

The binding energy for the initiated ${ }^{\mathbf{1}} \mathbf{C o}(\mathbf{0})-\mathbf{1}$ with the ethylene is $-2.86 \mathrm{kcal} / \mathrm{mol}$, resulting ${ }^{\mathbf{1}} \mathbf{C o}(\mathbf{0})-\mathbf{2}$. Then, by overcoming a considerable overall energy barrier of $21.25 \mathrm{kcal} / \mathrm{mol}$, the coordinated ethylene inserts into the $\mathrm{Co}-\mathrm{C}$ bond in ${ }^{1} \mathrm{Co}(0)-2$, producing the cobalt alkyl complex ${ }^{1} \mathbf{C o}(0)-3\left(\mathrm{LCoC}_{3} \mathrm{H}_{7}\right)$ with releasing energy of $-23.62 \mathrm{kcal} / \mathrm{mol}$. The second ethylene insertion (Ins II) starts from 3 reacting with the second ethylene, which was separated from the Ins I in Figure 1 for clarity. The energy barrier of Ins II is much higher than the Ins I. However, it could be compensated partly by the releasing energy from the formation of ${ }^{1} \mathbf{C o}(0)-3$, then the overall barrier for Ins II will be $9.50 \mathrm{kcal} / \mathrm{mol}$. Additionally, in comparison with the first one $(-2.86 \mathrm{kcal} / \mathrm{mol})$, the coordination of the second ethylene to ${ }^{1} \mathbf{C o}(0)-3$ is unfavorable (binding energy of $7.47 \mathrm{kcal} / \mathrm{mol}$ ). These results indicate that, in the ethylene polymerization catalyzed by the active species with similar electronic properties to the neutral Co(0)-1, the first ethylene insertion process could be the rate-determining step with exothermic energies ready for further reactions.

As shown in Scheme 1, after the formation of ${ }^{1} \mathbf{C o}(0)-3$, three reaction pathways could proceed: second insertion (Ins II) for chain growth, $\beta$-hydrogen transfer (BHT) and $\beta$-hydrogen elimination (BHE) for chain terminations. BHE just requires transferring the $\beta$-hydrogen to the metal center while Ins II and BHT need to coordinate another ethylene firstly. Obviously, the BHE process is more advantageous than BHT and Ins II. The overall barrier of BHE in the triplet state is $4.37 \mathrm{kcal} / \mathrm{mol}$, while it is only $1.99 \mathrm{kcal} / \mathrm{mol}$ in the singlet TS via a spin crossover. Then the singlet BHE complex ${ }^{0} \mathrm{Co}(0)-9$ is provided. Since the overall barrier of the BHT is much higher than that of BHT and Ins II reaction paths, it will not be considered as a termination process for the neutral cobalt alkyls species. So BHE process is kinetically favored over the thermodynamically favored Ins II to form the 
propagated cobalt alkyl complexes by $7.5 \mathrm{kcal} / \mathrm{mol}$. For the bis(imino)pyridyl metal species with low steric substituents, the BHE is competitive chain termination mechanism for producing short oligomer chains with unsaturated end group [44].

Figure 2 shows the binding information of the ethylene coordinated ${ }^{0} \mathrm{Co}(0)-2,{ }^{1} \mathbf{C o}(0)-2,{ }^{1} \mathbf{C o}(0)-4$ and ${ }^{1} \mathbf{C o}(0)-6$. The binding energy $\Delta E$ is defined as $\Delta E=E_{2}-\left(E_{1}+E_{\mathrm{C} 2 \mathrm{H} 4}\right)$ where $E_{2}$ refers to the zero point energies of the coordinated species ${ }^{1} \operatorname{Co}(0)-2$ or ${ }^{1} \operatorname{Co}(0)-4$ etc., and $E_{1}$ is for the precoordinated ${ }^{1} \operatorname{Co}(0)-1$ or ${ }^{1} \mathbf{C o}(\mathbf{0})-3$. It is found that the distance between the cobalt atom and the coordinated ethylene in ${ }^{0} \mathbf{C o}(\mathbf{0})-2$ is smaller than ${ }^{1} \mathbf{C o}(0)-2$ complex $(2.08,2.08 \AA$ vs $2.43,2.33 \AA)$. The double bond of the coordinated ethylene is longer in the ${ }^{\mathbf{0}} \mathbf{C o}(\mathbf{0})-\mathbf{2}(1.39 \AA)$ than ${ }^{1} \mathbf{C o}(\mathbf{0})-\mathbf{2}(1.35 \AA)$. These exhibited stronger interactions in ${ }^{0} \mathbf{C o}(0)-2$ than in ${ }^{1} \mathbf{C o}(0)-2$. However, the binding energy of ${ }^{1} \mathbf{C o}(0)-2$ has negative values $(-2.86 \mathrm{kcal} / \mathrm{mol})$ while it is positive in ${ }^{0} \mathbf{C o}(0)-2(3.63 \mathrm{kcal} / \mathrm{mol})$. Asymmetrical coordination was found between the bis(imino)pyridyl ligand and the cobalt metal center in ${ }^{1} \mathbf{C o}(0)-2$, as may contribute to the more binding energies than ${ }^{0} \mathbf{C o}(0)-2$ The asymmetric coordination could be easily observed from the distances between cobalt metal center and the nitrogen atoms in the bis(imino)pyridyl ligand. They are 2.24, 1.95 and $2.24 \AA$ in ${ }^{1} \mathbf{C o}(\mathbf{0})-1$, while they turn to $2.71,2.03$ and $2.08 \AA$ in ${ }^{1} \mathbf{C o}(\mathbf{0})-2$. The same phenomena was also observed in the ethylene coordinated ${ }^{1} \mathbf{C o}(\mathbf{0})-4$ and ${ }^{1} \mathbf{C o}(0)-6$, which is the intermediates for the further Ins II or BHT reactions. It is special to find this kind of asymmetrical coordination between the PDI ligand and the metal atom in the neutral triplet cobalt species. Therefore, the PDI ligand is bidentate rather than tridentate when interacts with the cobalt (Figure 2). As reported for the structure of the iron species, it is generally considered that the active center is 14-electron alkyl divalent cation structure [42,45]. It can be speculated that the cobalt species may also become a 14-electron structure by forming the bidentate coordination structure during the process of catalyzing ethylene polymerization. Chirik et al. [10] speculate that when bis(imino)pyridyl cobalt catalyzes the $[2+2]$ cycloadditions, the cobalt will de-coordinate with one of the nitrogen on both sides, which is consistent with the optimized intermediate structure ${ }^{1} \mathbf{C o}(0)-2$ and ${ }^{1} \operatorname{Co}(0)-4$. This special intermediate may provide new electronic properties for the interactions between the cobalt complexes and the coordinated ethylene.
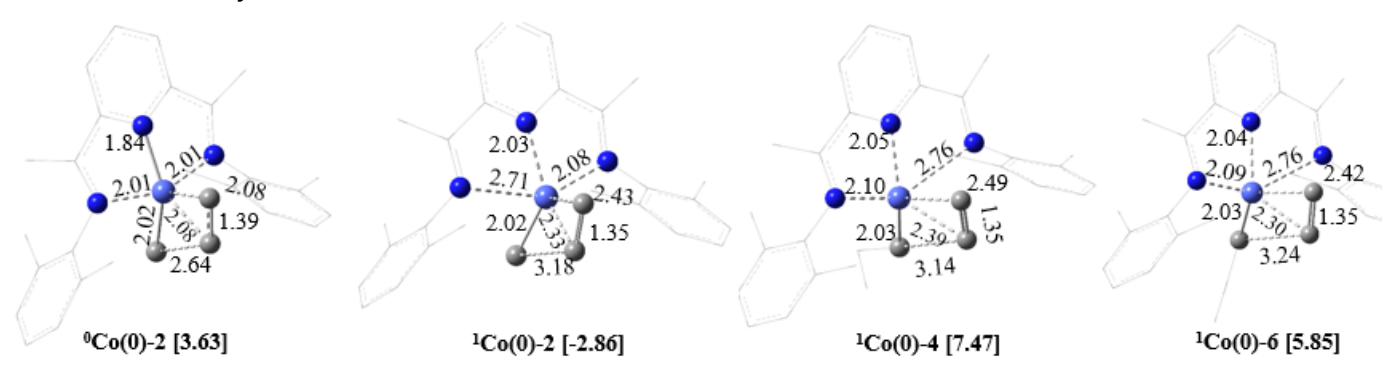

Figure 2. Optimized geometries of the ethylene coordinated cobalt alkyl complexes ${ }^{1} \mathbf{C o}(0)-2,{ }^{1} \mathbf{C o}(0)-4$ and ${ }^{1} \mathbf{C o}(0)-6$. (Distances are given in angstrom $(\AA)$, bonding energy is given in the bracket in $\mathrm{kcal} / \mathrm{mol}$ ).

In the transition state (TS) structures of ethylene insertion ${ }^{0} \mathbf{C o}(0)-2 / 3$ and ${ }^{1} \operatorname{Co}(0)-2 / 3$ (see Supporting Information Figures S1 and S2), the distance between the cobalt atom and $\gamma$-hydrogen on the connected polymer chain indicates an agnostic interaction leading to stabilization of structure. Further, the bidentate interactions recover to the tridentate manner during the transition state process.

To further clarify the special unsymmetrically bidentate NN coordination character in the $\pi$-complexes ${ }^{1} \mathbf{C o}(0)$-2, Mayer bond order analysis was performed by Multiwfn [46]. The bond order of the bonds in the active center for ${ }^{1} \mathbf{C o}(0)-2$ and ${ }^{0} \mathbf{C o}(0)-2$ are listed in Table 1 where the concerned atom numbers are illustrated in Scheme 2. The greater the value of bond order, the stronger the bond between atoms. Usually, the bond order for one $\pi$-bond equals two, and for one $\sigma$-bond equals one.

As shown in Table 1, the bond order value of most carbon-carbons bond is greater than 1.4, but differs between the ${ }^{0} \mathbf{C o}(\mathbf{0})-2$ and ${ }^{1} \mathbf{C o}(0)$-2. The bond orders are 1.41/1.42 in the aromatic pyridine ring $(C(1) \sim C(5))$ for ${ }^{0} \mathbf{C o}(\mathbf{0})$-2, indicating well delocalized $\pi$-bonds. In contrast, less conjugation degree exist in the pyridine ring of ${ }^{1} \mathbf{C o}(0)-2$, which could be derived from the broad range of the bond order value (1.33 1.49) in the ring. 


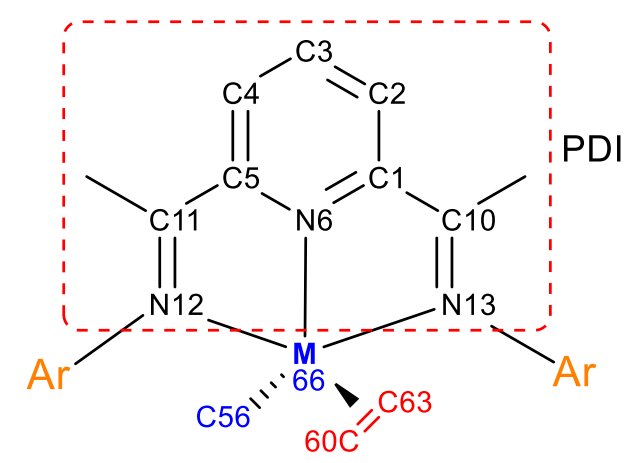

Scheme 2. Atom labels around the active centers and fragmental units for the ethylene coordinated ${ }^{s} \mathbf{M}(q)-2 \pi$-complexes. The hydrogen atoms were omitted for charity.

Table 1. Bond order of the bonds in the active center for ${ }^{1} \operatorname{Co}(0)-2$ and ${ }^{0} \operatorname{Co}(0)-2$ by Mayer bond order analysis ("-" represents coordination interaction and "-" represents a chemical bond).

\begin{tabular}{cccccc}
\hline Bonds & \multicolumn{2}{c}{ Bond Order } & \multicolumn{2}{c}{ Bonds } & \multicolumn{2}{c}{ Bond Order } \\
\hline & ${ }^{\mathbf{1}}$ Co(0)-2 & ${ }^{\mathbf{0}}$ Co(0)-2 & & ${ }^{\mathbf{1}}$ Co(0)-2 & ${ }^{\mathbf{0}}$ Co(0)-2 \\
\hline $\mathrm{C}(1)-\mathrm{C}(2)$ & 1.36 & 1.42 & $\mathrm{C}(10)-\mathrm{N}(13)$ & 1.44 & 1.47 \\
$\mathrm{C}(2)-\mathrm{C}(3)$ & 1.49 & 1.41 & $\mathrm{C}(11)-\mathrm{N}(12)$ & 1.82 & 1.48 \\
$\mathrm{C}(3)-\mathrm{C}(4)$ & 1.33 & 1.41 & $\mathrm{~N}(12)-\mathrm{Co}(66)$ & 0.11 & 0.47 \\
$\mathrm{C}(4)-\mathrm{C}(5)$ & 1.47 & 1.42 & $\mathrm{~N}(13)-\mathrm{Co}(66)$ & 0.39 & 0.48 \\
$\mathrm{C}(1)-\mathrm{N}(6)$ & 1.13 & 1.15 & $\mathrm{C}(56)-\mathrm{Co}(66)$ & 0.73 & 0.79 \\
$\mathrm{C}(5)-\mathrm{N}(6)$ & 1.25 & 1.15 & $\mathrm{C}(60)-\mathrm{C}(63)$ & 1.63 & 1.29 \\
$\mathrm{C}(1)-\mathrm{C}(10)$ & 1.23 & 1.24 & $\mathrm{C}(60)-\mathrm{Co}(66)$ & 0.24 & 0.54 \\
$\mathrm{C}(5)-\mathrm{C}(11)$ & 1.08 & 1.24 & $\mathrm{C}(63)-\mathrm{Co}(66)$ & 0.18 & 0.49 \\
$\mathrm{~N}(6)-\mathrm{Co}(66)$ & 0.42 & 0.61 & & & \\
\hline
\end{tabular}

As shown in Scheme 2, the $\mathrm{C}(11)-\mathrm{N}(12)$ and $\mathrm{C}(10)-\mathrm{N}(13)$ bonds could be considered as two 'arms' in bis(imino)pyridine skeleton. Both 'arms' and pyridine ring in ${ }^{0} \mathrm{Co}(0)$ have symmetrical bonding properties and exhibit good delocalized $\pi$-bond properties. However, unsymmetrical and localized bonding character were found in ${ }^{1} \mathbf{C o}(0)-2$. The bond order of $\mathrm{C}(1)-\mathrm{C}(10)(1.23)$ and $\mathrm{C}(10)-\mathrm{N}(13)(1.44)$ on one 'arm' are different from those of $\mathrm{C}(5)-\mathrm{C}(11)(1.08)$ and $\mathrm{C}(11)-\mathrm{N}(12)(1.82)$ on the other 'arm' in ${ }^{1} \mathbf{C o}(0)-2$, while they are almost the same in the ${ }^{0} \mathbf{C o}(0)-2$.

Further, the interactions between the cobalt metal and the three nitrogen atoms are intramolecular coordination bonds in which the bond order is mostly less than 0.5 . Among the three $\mathrm{Co}-\mathrm{N}$ interactions, stronger values were found between the central nitrogen on pyridine and the cobalt metal center. Additionally, they are weaker in ${ }^{1} \mathrm{Co}(0)-2$ than in ${ }^{0} \mathrm{Co}(0)-2$. The binding levels of $\mathrm{N}(6)-\mathrm{Co}(66)$, $\mathrm{N}(12)-\mathrm{Co}(66)$ and $\mathrm{N}(13)-\mathrm{Co}(66)$ are $0.42,0.11$ and 0.39 in ${ }^{1} \mathrm{Co}(0)-2$, but they are $0.61,0.47$ and 0.48 in ${ }^{0} \mathbf{C o}(0)-2$. The weak bond of the $\mathrm{N}(12)-\mathrm{Co}(66)(0.11)$ on one arm of the ${ }^{1} \mathbf{C o}(0)-2$ suggests that there is almost no coordination interaction between the $\mathrm{N}(12)$ and the cobalt metal. As a result, the cobalt atom has more interaction with one of the 'arms' $(\mathrm{C}(5)-\mathrm{C}(11)-\mathrm{N}(12))$ than the other, and the delocalization degree of this arm is smaller. Thus, the PDI ligand interacts with the cobalt in ${ }^{1} \mathbf{C o}(\mathbf{0})-\mathbf{2}$ by a bidentate coordination instead of the normal tridentate. By this way, the deficient 14-electron metal center may be created to inspire the activity of neutral cobalt LCo-R towards ethylene insertion.

In order to clearly demonstrate and compare the electronic properties of the ${ }^{1} \mathbf{C o}(0)-2$ and ${ }^{0} \mathbf{C o}(0)-2$, their HOMO orbitals were obtained by Multiwfn (Figure 3). The distribution of the HOMO orbitals of singlet ${ }^{0} \mathrm{Co}(0)-2$ are well symmetrically delocalized in the structures. In contrast, the distribution in triplet ${ }^{1} \operatorname{Co}(0)-2$ is asymmetric about the axis of the cobalt atom and the central nitrogen atom on the pyridine. This may be due to the fact the two unpaired electrons in ${ }^{1} \mathbf{C o}(0)-2$ arise the unsymmetrically bidentate NN coordination character. 


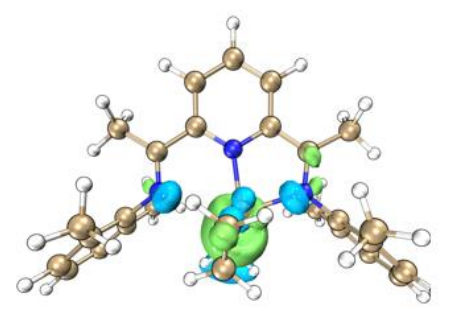

${ }^{1} \mathrm{Co}(0)-2$,

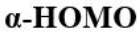

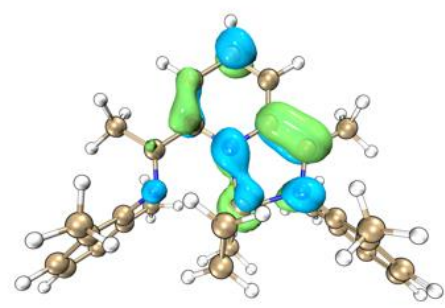

${ }^{1} \mathrm{Co}(0)-2$,

B-HOMO

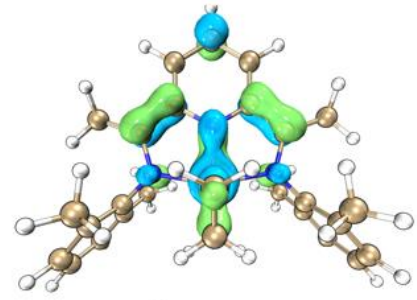

${ }^{0} \mathrm{Co}(0)-2$,

HOMO

Figure 3. HUMO orbitals of ${ }^{1} \mathbf{C o}(0)-2$ and ${ }^{0} \mathbf{C o}(0)$-2 (green; positive orbital phase and blue; negative orbital phase, isovalue of orbital is 0.05 ).

\subsubsection{Energy Profiles and Structures of the Cationic $\mathrm{LCo}^{+} \mathrm{CH}_{3}$ System}

As shown in Figure 4, zero point energy profiles of the cationic quartet $\left({ }^{3 / 2} \mathbf{C o}(+)\right)$ and the doublet $\left({ }^{1 / 2} \mathrm{Co}(+)\right)$ cobalt species are expressed by setting the energies of the reactants: ${ }^{1 / 2} \mathrm{Co}(+)-1$ and ethylene as the zero point. The optimized structures of all the points in Figure 4 are listed in Figures S3 and S4. For the $\mathrm{LCo}(+) \mathrm{CH}_{3}(\mathrm{Co}(+)-1)$ species, the doublet ${ }^{1 / 2} \mathrm{Co}(+)-1$ is more stable in energy than the quartet ${ }^{3 / 2} \mathrm{Co}(+)-1$ by $1.16 \mathrm{kcal} / \mathrm{mol}$. Differently, the ethylene coordinated Co(+)-2 is more stable in the quartet state than the doublet. It is interesting to find that for the cationic cobalt alkyl species, all the coordinated intermediates such as $\mathrm{Co}(+)-2, \mathrm{Co}(+)-4, \mathrm{Co}(+)-6, \mathrm{Co}(+)-7$ have lower energy in quartet than in doublet state. However, the transition process of Ins I and II prefer to proceed in doublet state instead of quartet. Overall, except for the two transition states Co(+)TS4/5 and Co(+)TS6/7, the energy differences between the quartet and the doublet states are not much within $3.5 \mathrm{kcal} / \mathrm{mol}$. This means that for the cationic cobalt alkyl species, the spin crossover may occur throughout the reaction pathway considered in Scheme 1.

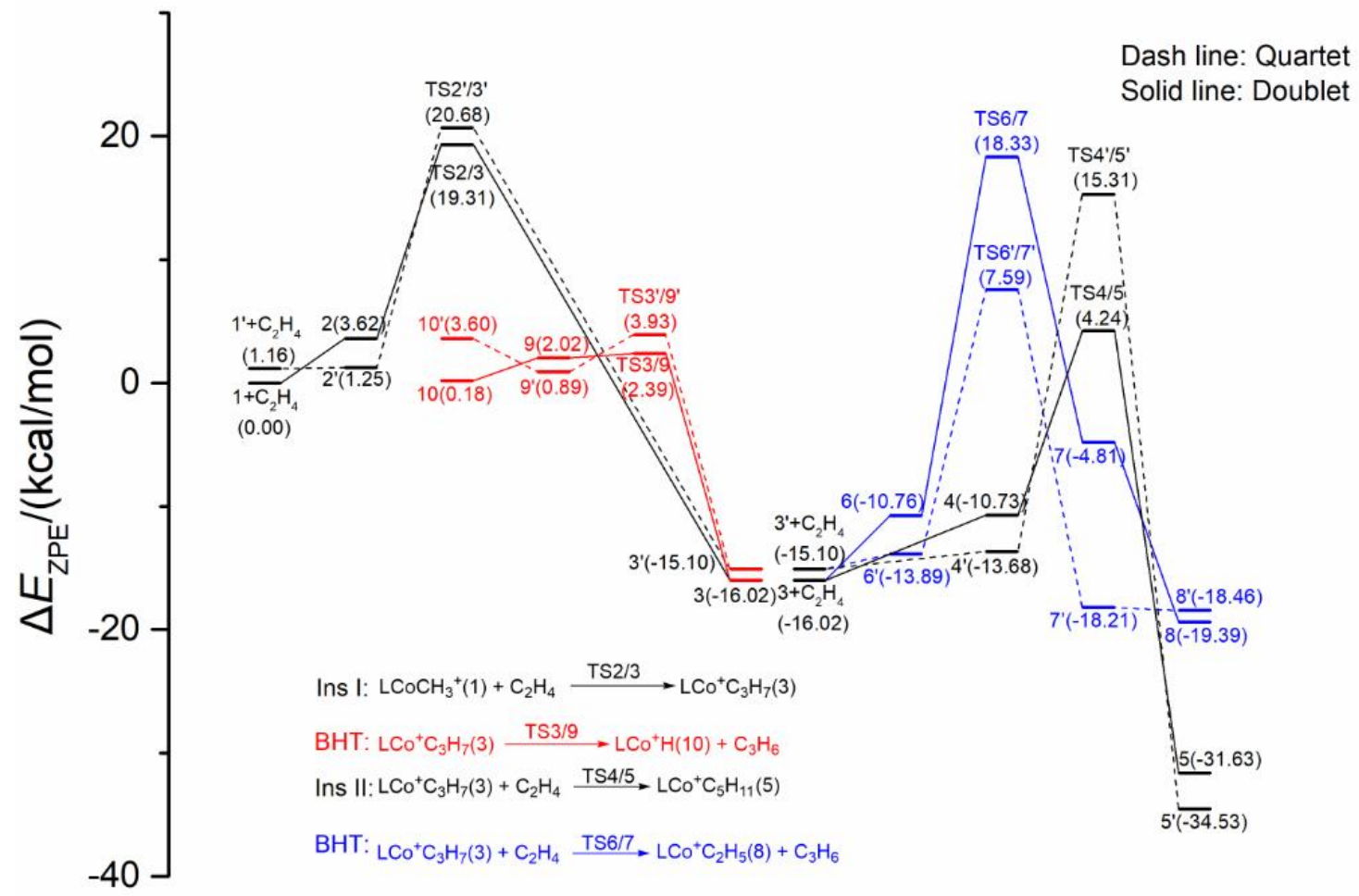

Figure 4. Energy profiles (kcal/mol) for the first and second ethylene coordination and insertion (black), $\beta-\mathrm{H}$ transfer (BHT, in blue) and $\beta$-H elimination (BHE, in red) catalyzed by the cationic cobalt complex in quartet (dash line) and doublet (solid line) spin states. The energies are relative zero-point energies with respect to the reactants: $\mathrm{LCo}^{+} \mathrm{CH}_{3}$ (1) (doublet state) and $\mathrm{C}_{2} \mathrm{H}_{4}$. The number $\boldsymbol{n}$ corresponds to $\mathrm{Co}(+)-\boldsymbol{n}$, the TS $m / n$ refers to the transition state between the two intermediates $\mathrm{Co}(+)-m$ and $\mathrm{Co}(+)-\boldsymbol{n}$. 
It is obvious that the overall energy barrier of the Ins I $(19.31 \mathrm{kcal} / \mathrm{mol})$ is higher than Ins II $(4.24 \mathrm{kcal} / \mathrm{mol})$, BHT $(7.59 \mathrm{kcal} / \mathrm{mol})$ and $\mathbf{B H E}(2.39 \mathrm{kcal} / \mathrm{mol})$, predicting the Ins I to be the rate determining step.

In comparison with the neutral cobalt species (Figure 1), the overall barrier for the process considered in Scheme 1 has lower energies for the corresponding cationic species (Figure 4). However, the energy released from the formation of the cobalt alkyl species is greater in the neutral system. For example, the energies of the overall transition barriers for Ins I and II in the neutral system are 21.25 and $9.5 \mathrm{kcal} / \mathrm{mol}$, respectively, while they are 19.31 and $4.24 \mathrm{kcal} / \mathrm{mol}$ in the cationic. The formation of the neutral ${ }^{1} \mathbf{C o}(0)-3$ and ${ }^{1} \mathbf{C o}(0)-5$ are -23.62 and $-42.74 \mathrm{kcal} / \mathrm{mol}$, respectively, while they are -15.10 and $-34.53 \mathrm{kcal} / \mathrm{mol}$ for ${ }^{3 / 2} \mathrm{Co}(+)-3$ and ${ }^{3 / 2} \mathrm{Co}(+)-5$. So, the cationic system may have better reactivities than the neutral one. The energy difference between the favorable BHE and the second favorable process Ins II is just $1.85 \mathrm{kcal} / \mathrm{mol}$ in $\mathbf{C o}(+)$ species while it is $7.51 \mathrm{kcal} / \mathrm{mol}$ in $\mathbf{C o}(\mathbf{0})$, indicating that the cationic species are more favorable for the chain propagation to generate polymers. The energetically unfavorable BHE in cationic could also facilitate the chain growth to polymers. For either the neutral or the cationic system, the Ins I is the rate-determining step.

Similar to the neutral $\pi$-coordinated species, the ${ }^{3 / 2} \mathrm{Co}(+)-4$ (quartet $4^{\prime}$ in Figure 4$)$ and ${ }^{3 / 2} \mathrm{Co}(+)-6$ (Figure S4) exhibits slightly asymmetry between metal center and nitrogen atoms in the bis(imino)pyridyl ligand.

\subsubsection{Energy Profiles and Structures of the Cationic $\mathrm{LFe}^{+} \mathrm{CH}_{3}$ System}

Previous theoretical works on the PDI-derived catalysts are mostly for cationic iron species. Ziegler examined the reactivity of the bis-ortho aryl substituted [(PDI)Fe $\left.\left(\mathrm{C}_{3} \mathrm{H}_{7}\right)\right]^{+}$complex towards ethylene polymerization by BP86 [35]. Along with transition states for Ins, BHT and BHE, metal-alkyl and ethylene $\pi$ coordination structures were reported. However, only singlet spin state energy profile was reported [40]. Later, Musaev reported the same structures and catalytic behaviors by B3LYP, in which high spin-state structures are more favorable. They also found that the BHT is favorable than the Ins process when the ligand steric is low. By B3LYP methods, the reactivity of the [(PDI)Fe $\left.\left(\mathrm{CH}_{3}\right)\right]^{+}$ was studied by de Bruin [47]. It was suggested that the termination via the BHT transition state has around $10 \mathrm{kcal} / \mathrm{mol}$ lower activation enthalpy than ethylene insertion. Further, the $\left[(\mathrm{PDI}) \mathrm{Fe}\left(\mathrm{CH}_{3}\right)\right]^{2+}$ with iron in +III oxidation state has a much lower insertion barrier than BHT.

In order to compare the different charge effect between iron and cobalt complexes the computational study was carried out on both of the neutral and cationic bis(imino)pyridine (PDI) iron complexes. The energy profiles for the cationic PDI iron species were depicted in Figure 5. Further, the optimized structures were listed in Figures S5 and S6. For most of the points shown in Figure 5, the quintet state is more stable in energy than the triplet state. The transition state of Ins II located on the triplet spin state is consistent with the results reported by Musaev who has examined the ethylene insertion to the $\left[(\mathrm{PDI})-\mathrm{FeC}_{3} \mathrm{H}_{7}\right]^{+}$structure [47].

Similar to the cobalt species, Ins I process is also the rate determining step. Close overall transition barriers were found for the three reaction pathways of Ins II, BHT, and BHE in the cationic iron species, in which the energy difference is just $3.14 \mathrm{kcal} / \mathrm{mol}$. It seems that the $\mathbf{B H E}$ has lower transition energy. However, BHE is an energetically unfavorable process producing ${ }^{2} \mathbf{F e}(+)$ and $\mathrm{C}_{3} \mathrm{H}_{6}$, with endothermal energy of $2.75 \mathrm{kcal} / \mathrm{mol}$.

Despite the transition barrier is not high, the BHE process of both cationic cobalt and iron species occurs with a bit endothermal energy. The overall energy of the rate-determining transition barrier is $19.35 \mathrm{kcal} / \mathrm{mol}$ in $\mathbf{F e}(+)$ while it is $19.31 \mathrm{kcal} / \mathrm{mol}$ in $\mathbf{C o}(+)$. Identical reactivity may exist in the cationic iron and cobalt systems. However, it is difficult for the active species to possess strictly positive charge in the actual catalytic process, since the anion ions interact with them more or less in the real experiments. 


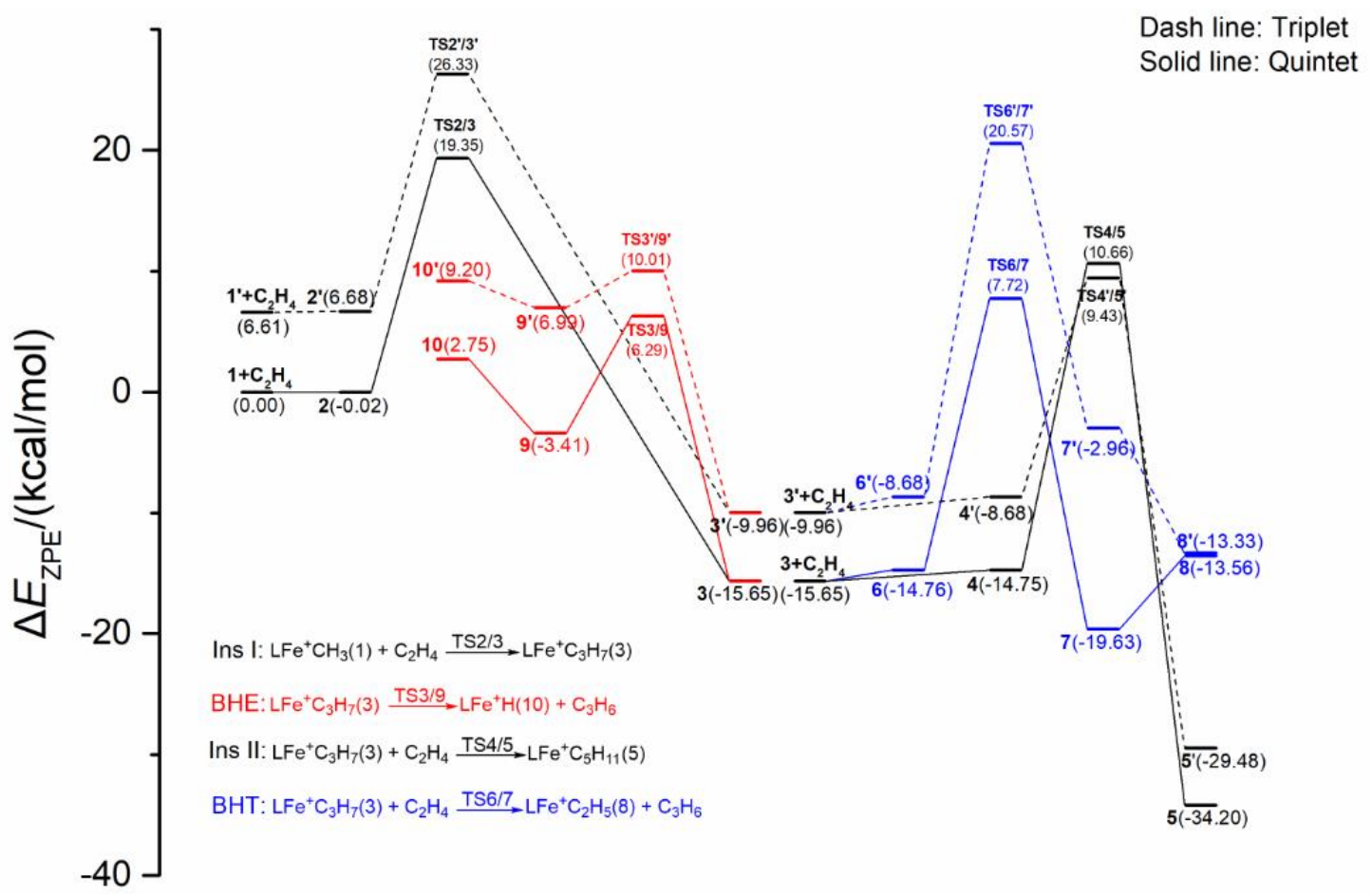

Figure 5. Energy profiles (kcal/mol) for the first and second ethylene coordination and insertion (black), $\beta-\mathrm{H}$ transfer (BHT, in blue) and $\beta-\mathrm{H}$ elimination (BHE, in red) catalyzed by the cationic iron complex in triplet (dash line) and quintet (solid line) spin states. The energies are relative zero-point energies with respect to the reactants: $\mathrm{LFeCH}_{3}(+)(\mathbf{1})$ (quintet state) and $\mathrm{C}_{2} \mathrm{H}_{4}$. The number $n$ corresponds to $\mathbf{F e}(+)-n$, the TS $m / n$ refers to the transition state between the two intermediates $\mathrm{Fe}(+)-\boldsymbol{m}$ and $\mathrm{Fe}(+)-\boldsymbol{n}$.

\subsubsection{Energy Profiles and Structures of the Neutral $\mathrm{LFeCH}_{3}$ System}

As shown in Figure 6, the energy profiles for the neutral iron species Fe(0) were illustrated and the optimized structures were listed in Figures S7 and S8. Almost all the quartet state species is more stable in energy than doublet state species, indicating that for neutral bis(imino)pyridyl (PDI) iron complexes, doublet state species have an overwhelming superiority.

The barrier for Ins I is also the rate determining step for $\mathbf{F e}(\mathbf{0})$. The value for it is $16.13 \mathrm{kcal} / \mathrm{mol}$, as it is lower than either neutral $\mathbf{C o}(0)$ or cationic $\mathbf{C o}(+)$ and $\mathbf{F e}(+)$. Different from $\mathbf{F e}(+)$ and $\mathbf{C o}(0)$, the BHT process for $\mathbf{F e}(\mathbf{0})$ is more favorable than the BHE. Overall, in comparison with Ins II and BHE, the BHT is the most preferred reaction paths. Similar with neutral Co(0), the neutral iron alkyl intermediates $\mathbf{F e}(\mathbf{0})-3$ and $\mathbf{F e}(\mathbf{0})-5$ are very stable with considerable exothermic energies indicating that the neutral systems tend to form stable metal alkyls. Moreover, the binding energies of ${ }^{3 / 2} \mathbf{F e}(0)-1$ with ethylene to form ${ }^{3 / 2} \mathbf{F e}(\mathbf{0})-\mathbf{2}$ is $-5.74 \mathrm{kcal} / \mathrm{mol}$, which is more stable than that of ${ }^{1} \mathbf{C o}(\mathbf{0})-\mathbf{2}$. However, it may be due to the one less electron in the ${ }^{3 / 2} \mathbf{F e}(0)-2$ than the ${ }^{1} \mathrm{Co}(0)-2$, the unsymmetrical coordination has not been observed in the neutral iron system.

\subsection{General Electronic Properties}

\subsubsection{Oxidation Level of the PDI Ligand}

Wieghardt and colleagues found a structural parameter $(\Delta)$ to determine electron exchange between the metal and the bis(imino)pyridyl ligand along with the oxidation level of metal according to the following Equation (1) [29];

$$
\Delta=\left[\left(\mathrm{d} 2+\mathrm{d} 2^{\prime}\right) / 2-\left(\mathrm{d} 1+\mathrm{d} 1^{\prime}+\mathrm{d} 3+\mathrm{d} 3^{\prime}\right) / 4\right]
$$


Each factor was defined as depicted in Scheme 3. Based on the equation, we found the changes linearly with the reduction of $\left(\mathrm{PDI}^{0}\right)$ ligand. This finding could be helpful for the electronic exchange definitions between the metal and bis(imino)pyridine skeleton structure.

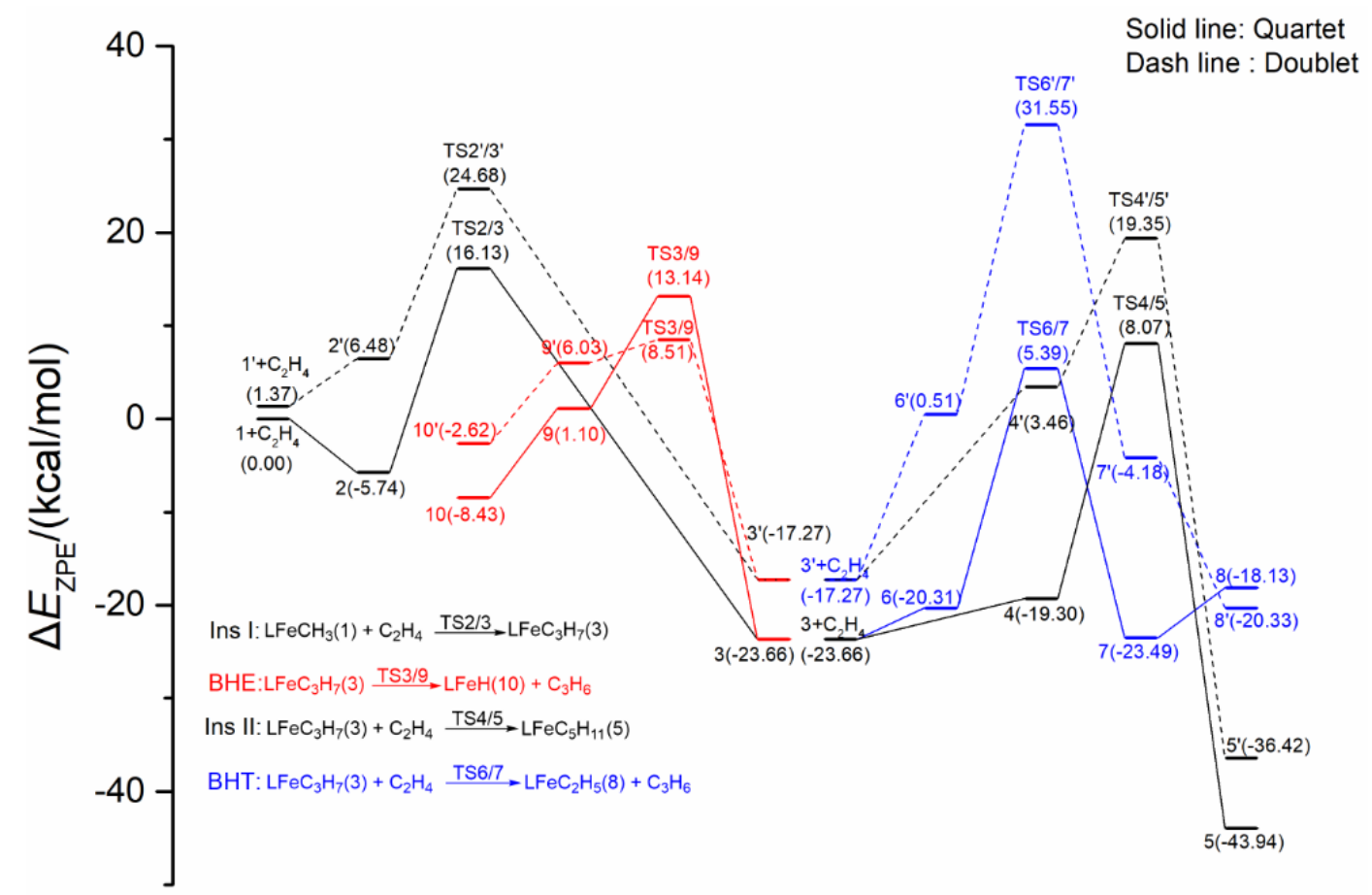

Figure 6. Energy profiles (kcal/mol) for the first and second ethylene coordination and insertion (black), $\beta-\mathrm{H}$ transfer (BHT, in blue) and $\beta-\mathrm{H}$ elimination (BHE, in red) catalyzed by the neutral iron complex in doublet (dash line) and quartet (solid line) spin states. The energies are relative zero-point energies with respect to the reactants: $\mathrm{LFeCH}_{3}\left(\mathbf{1}\right.$, quartet state) and $\mathrm{C}_{2} \mathrm{H}_{4}$. The number $\boldsymbol{n}$ corresponds to $\mathbf{F e}(\mathbf{0})-\boldsymbol{n}$, the TS $m / n$ refers to the transition state between the two intermediates $\mathrm{Fe}(0)-\boldsymbol{m}$ and $\mathrm{Fe}(0)-\boldsymbol{n}$.

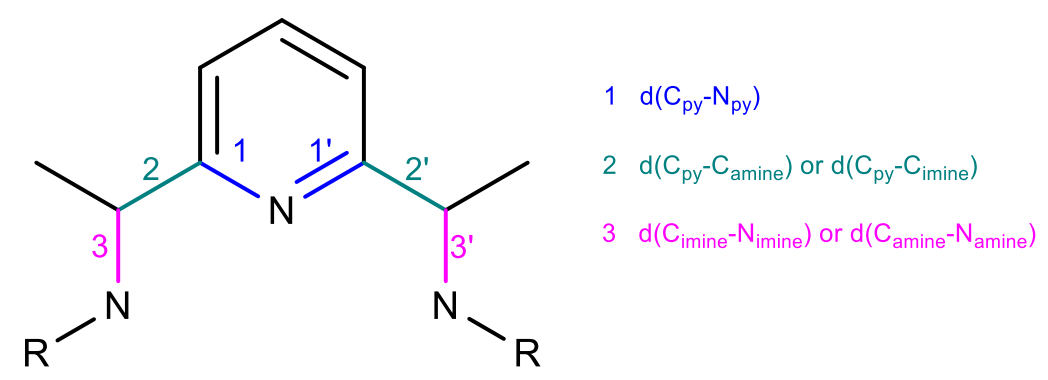

Scheme 3. Definition of the factors to calculating the structure parameter $\Delta$ in the bis(imino)pyridine (PDI) skeleton structure.

To figure out how the electronic exchange occurred between the metal and the bis(imino)pyridine skeleton structure, we calculated the $\Delta$ value of the structures for the Ins I and II process and listed in Figure 7 (for more details see Supporting Information in Tables S1-S8).

It is necessary to have an overall cognition about the structure parameter $\Delta$ of iron and cobalt species before analyzing the data in Figure 7 . It is characteristic of neutral (PDI) ${ }^{0}$ ligands when the values are in the range of $0.15-0.19 \AA$ (av $0.17 \AA$ ). The $\Delta_{\exp }$ values in the range $0.09 \sim 0.12 \AA$ (average, $0.102 \AA$ ) are typical for a $\pi$-radical anion $(\mathrm{PDI})^{1-}$. Structures with an average $\Delta_{\text {exp }}$ value of $0.062 \pm 0.02 \AA$ have been found for complexes containing a dianion (PDI) ${ }^{2-}$. Having this in mind, the calculated $\Delta$ in this work will reflect the oxidation level of the PDI ligand. 


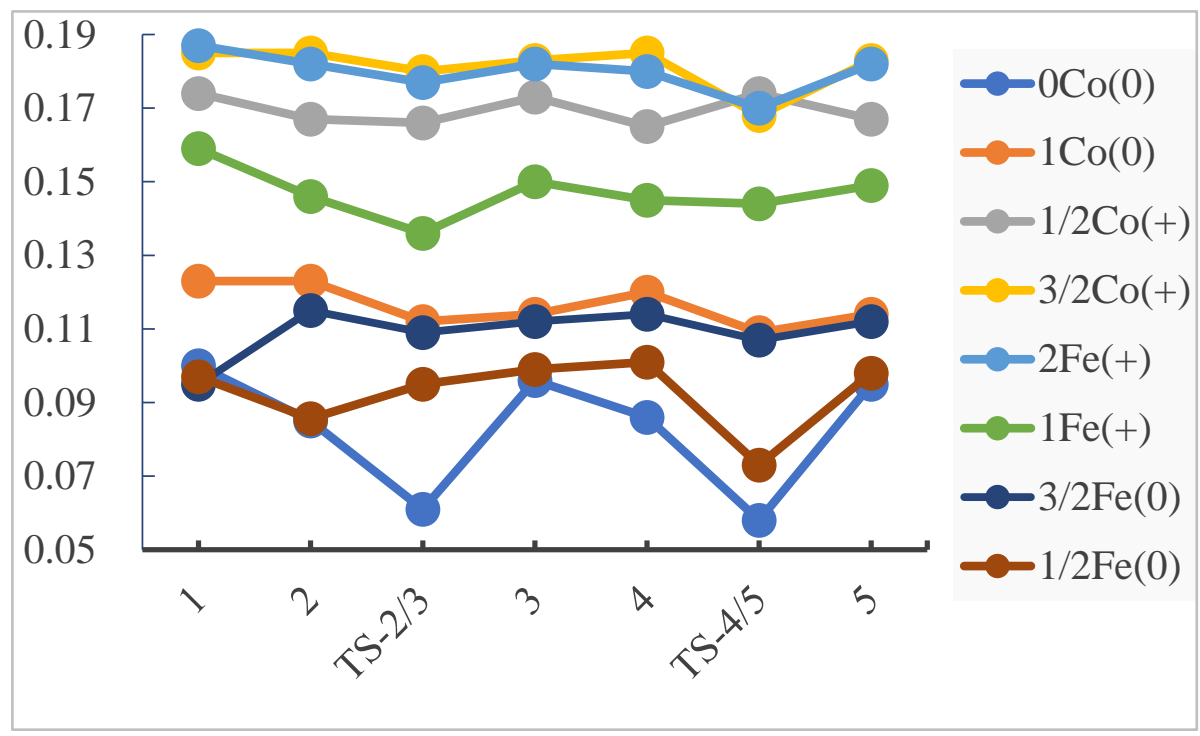

Figure 7. The structure parameter $\Delta$ calculated for both iron and cobalt species.

As illustrated in Figure 7, it is clear that for most cationic systems, the calculated values $\Delta$ are located in the range of $0.15 \sim 0.19 \AA$, which indicates that the PDI ligands are neutral. Then, the oxidation state of the metal center will be $+\mathrm{II}$, which is normally accepted in the related reports. There are some differences between the high and low spin states for the cationic species, in which the latter has lower values than the former. This means that the interactions between the PDI ligand and metal center are stronger in the low spin state than the high spin state. Further, it could also be supported from the shorter bond in optimized structures in Figures S1-S8. In comparison with the iron system, the values of the cationic cobalt species are always greater. Especially for the low spin cationic species, the values of iron system are in the range of $0.144 \sim 0.159$ while they are $0.165 \sim 0.174$ for cobalt. The values for the high spin states are almost the same for the iron and cobalt species.

For most of the neutral iron and cobalt structures, the $\Delta$ values are within $0.09 \sim 0.13 \AA$. Theoretically, that the PDI ligand is an anion revealing the +II oxidation level of the metal center in the neutral $\mathrm{LMCH}_{3}$ structure, which is exhibits as $+\mathrm{I}$ in appearance. According to the results mentioned above, the ground state of these neutral species is high spin state. It is similar to the cationic species, the $\Delta$ values for high spin states are almost the same for iron and cobalt system. However, lower values are found in ${ }^{0} \mathbf{C o}(0)$ structures. Particularly, the $\Delta$ values of the transition barrier for the Ins I and Ins II in ${ }^{0} \mathrm{Co}(\mathbf{0})$ are rather low. They are 0.061 and 0.058 , respectively, suggesting that PDI is dianion during the insertion step.

Overall, in comparison with the cationic species, the one more extra electron in the neutral species may mainly transfer to the PDI ligand instead of the metal center. By this way, the metal center does always keep the + II valence in either cationic or neutral species.

\subsubsection{Charge Distribution}

In order to figure out the difference of the charge distribution among ${ }^{\mathrm{s}} \mathbf{M}(q)-\mathbf{1}$ and the ethylene coordinated ${ }^{\mathbf{s}} \mathbf{M}(q)-2$, we do the electronic population analysis by natural bond orbital (NBO) method [48]. Firstly, the model molecule in Scheme 2 is divided into four moieties: PDI ligand, $\mathbf{M}$ center, $\mathrm{CH}_{3}$ and two Ars (aromatic rings connected to the two nitrogen atoms in PDI ligand). The NBO charge distribution of ${ }^{\mathbf{s}} \mathbf{M}(q)-\mathbf{1}$ was illustrated in Figure 8a and Table S9. The charge changes aroused by the coordination of the ethylene in ${ }^{\mathrm{s}} \mathbf{M}(q)-2$ were listed in Figure $8 \mathrm{~b}$. 


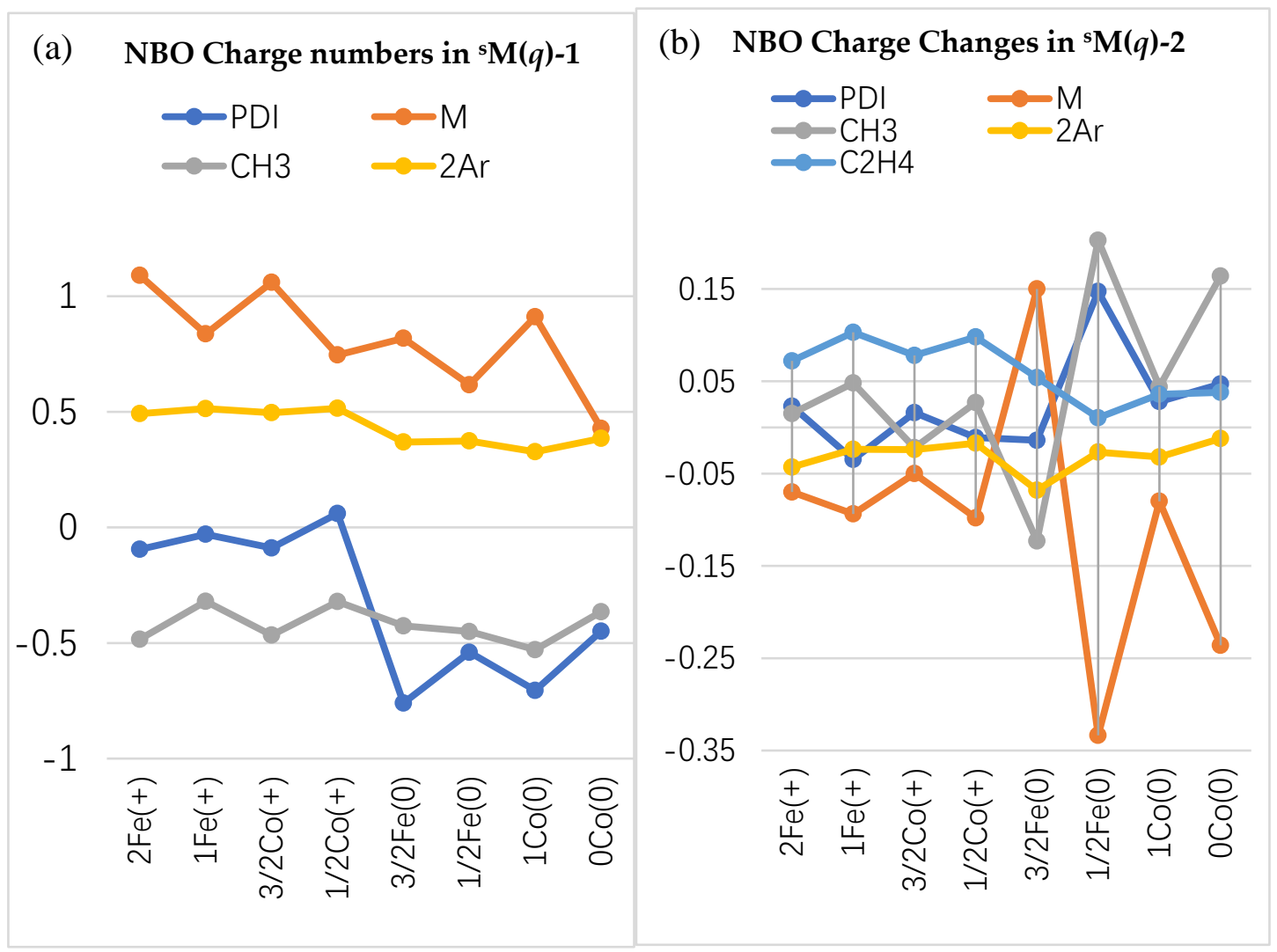

Figure 8. (a) The natural bond orbital (NBO) charge distribution for ${ }^{\mathbf{s}} \mathbf{M}(q) \mathbf{- 1}$ and (b) the charge changes aroused by ethylene coordination in ${ }^{\mathrm{s}} \mathbf{M}(q)-\mathbf{2}$, where $\mathrm{M}$ is iron or cobalt, $q$ is zero or positive, with high and low spin states.

As shown in Figure 8a, for both of the cationic and neutral species, the metal center and the two Ars possess positive charges while the $\mathrm{CH}_{3}$ moiety that binds to the metal has negative values. The positive values for the two Ars decrease slightly from the cationic species (0.492 0.515) to the neutral ones $(0.327 \sim 0.385)$. Similarly, the fluctuation of the negative charges in the $\mathrm{CH}_{3}$ moiety is also not great. Additionally, it is obvious that the cationic complex has more positive charges than the neutral. The NBO charge distributions here could strongly support the conclusion that the PDI ligand is almost neutral in the cationic species while it is anion in the neutral species. The charge values of PDI in both of the neutral iron and cobalt species are close to zero while they are the most negative moiety in the neutral species. Therefore, the loss of one electron from the neutral system is mainly from the PDI ligand instead of the metal center.

After coordination of ethylene molecules, the charge distribution changes slightly in the cationic species while it changes more in the neutral species. In ${ }^{\mathrm{s}} \mathbf{M}(q)-2$, the $\mathrm{C}_{2} \mathrm{H}_{4}$ moiety has positive NBO charges in both cationic and neutral systems, indicating that some of the electrons from $\mathrm{C}_{2} \mathrm{H}_{4}$ are transferred to other moieties, mainly to the metal center. Additionally, the electrons transferred from $\mathrm{C}_{2} \mathrm{H}_{4}$ moiety are less in the neutral ${ }^{\mathbf{s}} \mathbf{M}(0)-2$ than the cationic ${ }^{\mathbf{s}} \mathbf{M}(+)-2$. Besides the metal center, there are significant changes of charges on the $\mathrm{CH}_{3}$ and PDI moieties in the neutral due to the coordination. For ${ }^{3 / 2} \mathrm{Fe}(0)-2$, the iron atom become more positively charged while $\mathrm{CH}_{3}$ moiety is more negatively. In contrast, for the ${ }^{1 / 2} \mathrm{Fe}(0)-2,{ }^{1} \mathrm{Co}(0)-2$ and ${ }^{0} \mathrm{Co}(0)-2$, the metal atoms receive less positive charges while $\mathrm{CH}_{3}$ less negative.

\subsubsection{General Comparison on Valence Electrons}

For all the four species, $\mathbf{C o}(+), \operatorname{Co}(0), \mathrm{Fe}(+), \mathbf{F e}(0)$, the first ethylene insertion step is the rate determining one. Additionally the energies of the transition barriers increase in the sequence of $\mathbf{F e}(\mathbf{0})$ 
$(16.13 \mathrm{kcal} / \mathrm{mol})<\mathrm{Co}(+)(19.31 \mathrm{kcal} / \mathrm{mol})<\mathrm{Fe}(+)(19.35 \mathrm{kcal} / \mathrm{mol})<\mathrm{Co}(0)(21.25 \mathrm{kcal} / \mathrm{mol})$, though the difference is not much, within $5.12 \mathrm{kcal} / \mathrm{mol}$. The neutral cobalt system $\mathbf{C o}(\mathbf{0})$ has the lowest reactivity because it possesses the most more electrons; however, the $\mathbf{F e}(+)$, which lacks the electrons most, is not the most active one here. As for the spin states of the $\mathbf{C o}(+), \mathbf{F e}(\mathbf{0})$, and $\mathbf{F e}(+)$, Ins I and Ins II process have lower energy in the high spin states, but spin crossover may exist for the BHT and BHE process in most cases. Additionally, the spin crossover is almost throughout the Co(+) species. BHT or BHE is the kinetically favorable process in comparison with the Ins II as they have a low steric substituent, but they are always energetically unfavorably. The $\mathbf{C o}(0)$ and $\mathbf{F e}(+)$ tend to undergo hydrogen transfer through BHE for the possible chain termination, while Fe(0) and Co(+) through BHT.

As demonstrated in Scheme 4, the valence electron numbers were considered generally. The unpaired electron numbers are the same for $\mathbf{C o}(+)$ and $\mathbf{F e}(0)$, which is one electron less, and better reactivity, than the Co(0). Additionally, the unpaired electrons are located mainly at the cobalt metal center for $\mathbf{C o}(+)$ whereas those in $\mathbf{F e}(\mathbf{0})$ are distributed in both of the iron metal and the PDI ligand. This may explain the occurrence of more spin crossover in $\mathbf{C o}(+)$ system. Additionally, the loss of one electron from the $\mathbf{C o}(0)$ to form the $\mathbf{C o}(+)$ is mainly from the PDI ligand instead of the cobalt metal, as is the same for $\mathbf{F e}(\mathbf{0})$ to $\mathbf{F e}(+)$. The better reactivity of neutral $\mathbf{F e}(\mathbf{0})$ may be attributed to the almost $14 \mathrm{e}$ deficient electrons around the iron atom. For the cobalt species, it could also reach the $14 \mathrm{e}$ center by losing the $\mathrm{CH}_{3}$ anion group from $\mathbf{C o}(0)$ to afford the $\mathbf{C o}(+)^{\mathbf{B}}$ (the symbol B to mark the bare nature or no alkyl coordination of the cobalt center) which could be supported by the observation of the alkyl free intermediate in the experiment $[27,28]$. In the next part, the coordination of ethylene or the cocatalyst anion groups to the $\mathbf{C o}(+)^{\mathbf{B}}$ will be analyzed for the possible reaction mechanism.

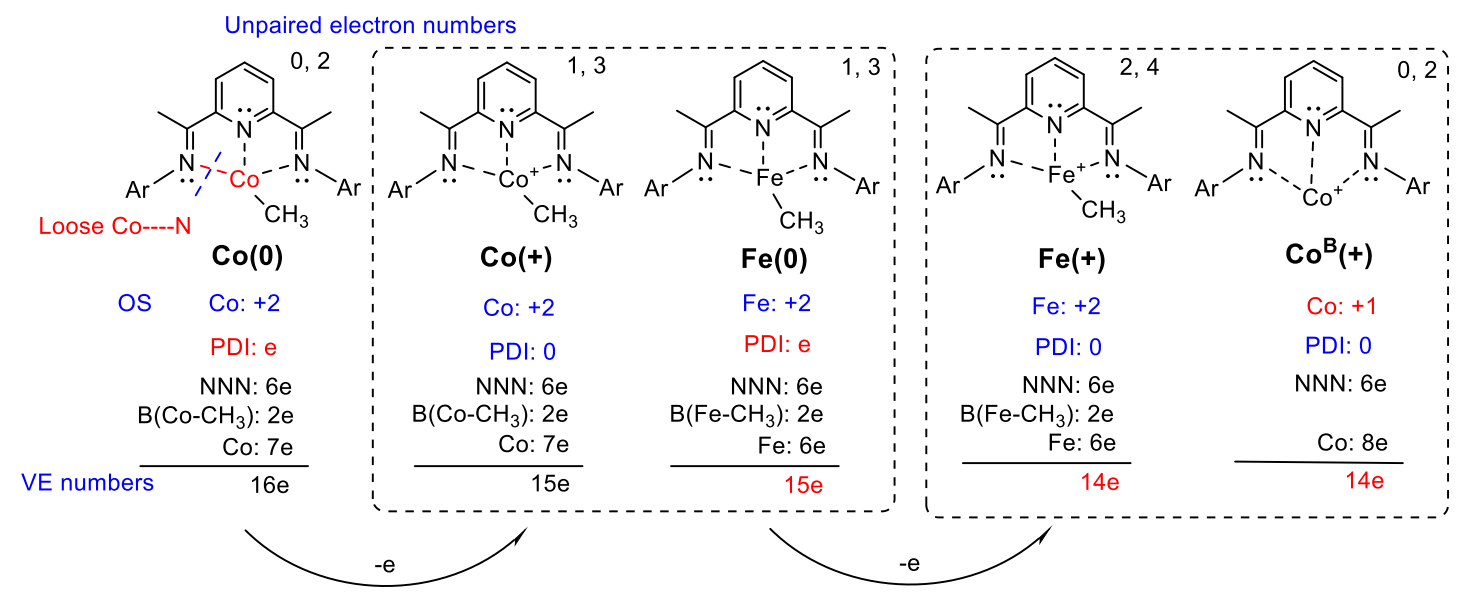

Scheme 4. The oxidation states of the metal center and the PDI ligand, the numbers of the valence electrons around the metals.

It is worth mentioning that the numbers of the valence electrons in Co(0) is 16e, but when one of the nitrogen atoms in the PDI lost interactions with the metal center (as shown in Scheme 4), the 14e deficient center may be formed by an unsymmetrical manner. The good activity in the single cyclopenta ring fused PDI cobalt system towards the ethylene oligomerization in the experiments [49] could be attributed to the NNN unsymmetrically loose coordination manner in the metal center.

\subsection{Possible Catalytic Process for the Cobalt Species}

The electron deficient metal alkyl species $[\mathrm{LM}-\mathrm{R}]^{+}$was well accepted mode for both early and late transition metal complexes when $\mathrm{L} n \mathrm{MX}_{2}$ activated by MAO. However, Gibson $[27,28]$ reported that the active species for cobalt species is anticipated to be the $[\mathrm{LCo}]^{+}$instead of the cobalt alkyl cation $[\mathrm{LCO}-\mathrm{R}]^{+}$. Strong coordinating interactions were found for $[\mathrm{LM}]^{+}$cation with the anions [Cl-MAO] $^{-}$or [Me-MAO] $]^{-}$derived from cocatalysts. In the NMR investigation by Talsi et. al [34], neutral complexes of $\mathrm{LCo}(\mu-\mathrm{Me})_{2} \mathrm{AlMe}_{2}$ were observed in the catalyst systems $\mathrm{LCoCl}_{2} / \mathrm{AlMe}_{3}$. However, 
in the presence of ethylene, the proposed structure of $\left[\mathrm{LCo}\left(\eta-\mathrm{C}_{2} \mathrm{H}_{4}\right)\right]^{+}\left[\mathrm{AlMe} \mathrm{Cl}_{3}\right]^{-}$is the major cobalt species. The polymerization manner catalyzed by the cobalt complex initiated with cocatalysts is still unclear. Even the exact nature of MAO and MMAO remains somewhat unclear, previous computational work showed that explicit inclusion of a MAO model did not significantly alter energy and structures for modeling ethylene oligomerization [50]. Thus, the $\left[\mathrm{AlMe}_{4}\right]^{-}$was considered as the anion ions that function as the cocatalysts.

To further explore the intrinsic mechanism of ethylene reactions catalyzed by the cobalt species, as depicted in Figure 9 and Scheme 5, we contrast the energy profiles of the reactions of $\mathbf{L}^{\mathbf{s}} \mathbf{C o}(+)^{\mathbf{B}}$ with $\mathrm{C}_{2} \mathrm{H}_{4}$ and anion ions $\left[\mathrm{CH}_{3}\right]^{-}$and $\left[\mathrm{AlMe}_{4}\right]^{-}$, respectively. Only the first ethylene insertion process was considered, as it appears to be the rate-determining step in the above calculated results. Both of the single and triplet states were considered with the optimized structures listed in Figures S9 and S10. The triplet is lower in energy than the singlet spin state. It was found that the reactions of both of the anion ions $\left[\mathrm{CH}_{3}\right]^{-}$and $\left[\mathrm{AlMe}_{4}\right]^{-}$with the $\mathbf{L}^{\mathbf{s}} \mathbf{C o}(+)^{\mathbf{B}}$ release plenty of energy, generating the neutral species $\mathbf{1 A}$ and $\mathbf{1 C}$. The coordination of the $\left[\mathrm{AlMe}_{4}\right]^{-}$to $\mathbf{L}^{\mathbf{1}} \mathbf{C o}(+)^{\mathbf{B}}$ is more stable in energy than the $\left[\mathrm{CH}_{3}\right]^{-}$by $15.48 \mathrm{kcal} / \mathrm{mol}$. This indicates that the similar anion ions $[\mathrm{Cl}-\mathrm{MAO}]^{-}$or $[\mathrm{Me}-\mathrm{MAO}]^{-}$derived from the cocatalysts may prefer to interact with the cobalt center closely to form the neutral species, instead of resulting the ion pairs with weak interactions.

In comparison with anion ions $\left[\mathrm{CH}_{3}\right]^{-}$and $\left[\mathrm{AlMe}_{4}\right]^{-}$, the coordination of $\mathrm{C}_{2} \mathrm{H}_{4}$ to the bare cationic $\mathbf{L}^{\mathbf{1}} \mathbf{C o}(+)^{\mathbf{B}}$ produces less energy, but the formation of the $\mathbf{L}^{1} \mathbf{C o}(+) \mathrm{C}_{2} \mathrm{H}_{4}(\mathbf{1 B})$ is still considerably stable in energy by $16.27 \mathrm{kcal} / \mathrm{mol}$. The electron deficient $14 \mathrm{e} \mathbf{L}^{1} \mathbf{C o}(+)^{\mathbf{B}}$ which is electron deficient has better binding abilities than either the cationic $\mathbf{L}^{3 / 2} \mathbf{C o}(+) \mathrm{CH}_{3}(3.62 \mathrm{kcal} / \mathrm{mol})$ or the neutral $\mathbf{L}^{1} \mathbf{C o}(\mathbf{0}) \mathrm{CH}_{3}$ $(-2.86 \mathrm{kcal} / \mathrm{mol})$ to coordinate the ethylene monomers. This may explain the experimental observation of the $\left.\mathbf{L C o}\left(\eta-\mathrm{C}_{2} \mathbf{H}_{4}\right)\right]^{+}$. Additionally, for the process of the ethylene insertion, the energy barrier for the $\left[\mathrm{AlMe}_{4}\right]^{-}$participating one is lower than the $\left[\mathrm{CH}_{3}\right]^{-}$by $5.46 \mathrm{kcal} / \mathrm{mol}$.

As mentioned above, the loss of electrons between the neutral and cationic species mainly caused the reduction of the oxidation state of the PDI ligand instead of the metal center. This means the metal center keeps the $+\mathbf{I I}$ valence state in both the neutral and cationic systems. The oxidation state of the PDI ligand in the processes in Figure 9 was monitored and compared by calculating the structure parameter $\Delta$. As listed in Table 2, similar to the cationic ${ }^{\mathbf{s}} \mathbf{C o}(+)-\mathbf{1}$, the $\Delta$ value of $\mathbf{L}^{\mathbf{1}} \mathbf{C o}(+)^{\mathbf{B}}$ is $0.181 \AA$, indicating the neutral character of the PDI ligand. Consequently, the valence state of the cobalt metal center in $\mathbf{L}^{1} \mathbf{C o}(+)^{\mathbf{B}}$ is $+\mathbf{I}$ instead of $+\mathbf{I I}$. The neutral PDI ligand and the $+\mathbf{I}$ valence cobalt metal center were retained in the ethylene coordinated cationic $\mathbf{L}^{1} \mathbf{C o}(+) \mathrm{C}_{2} \mathrm{H}_{4}(\mathbf{1 B}$ in Figure 9). However, the $\Delta$ values of $0.123 \AA, 0.119 \AA$ and $0.114 \AA$ for $\mathbf{1 A}, 1 \mathrm{C}$ and $3 \mathrm{~A} / \mathbf{3 B}$ indicated the presence of a monoanionic PDI ligand (more details see Tables S10 and S11). 2B could be generated from the 1B (neutral PDI and + I cobalt center) and 1C (monoanionic PDI and +II Cobalt center). Particularly, the calculated $\Delta$ value of the structure 2B appears to be $0.168 \AA$ which is in the range of the neutral PDI. Additionally, there is no $\mathbf{C o}-\mathbf{C} \sigma$ bond formed in $\mathbf{2 B}$, as is different from $\mathbf{2 A}$. In $\mathbf{2} \mathbf{B}$, the carbon atom in methyl group forms $\sigma$ bond neither with Cobalt nor with Aluminum. Thus, the bonding in $\mathbf{2 B}$ appears to be a 3-center 2-electron character. Additionally, the valence state of cobalt should be $+\mathbf{I}$ in $2 B$. Moreover, the interaction of the cobalt atom with the $\left[\mathrm{AlMe}_{4}\right]^{-}\left(\mathrm{Co}-\mathrm{C}\left(\left[\mathrm{AlMe}_{4}\right]^{-}\right), 2.39 \AA\right)$ is less strong than with the coordinated ethylene $\left(\mathrm{Co}-\mathrm{C}\left(\mathrm{C}_{2} \mathrm{H}_{4}\right), 2.02 \AA\right)$. The chain growth in the cobalt species may proceed by attacking the carbon atom of the binding $\mathrm{C}_{2} \mathrm{H}_{4}$ from the methyl group in $\left[\mathrm{AlMe}_{4}\right]^{-}$. 


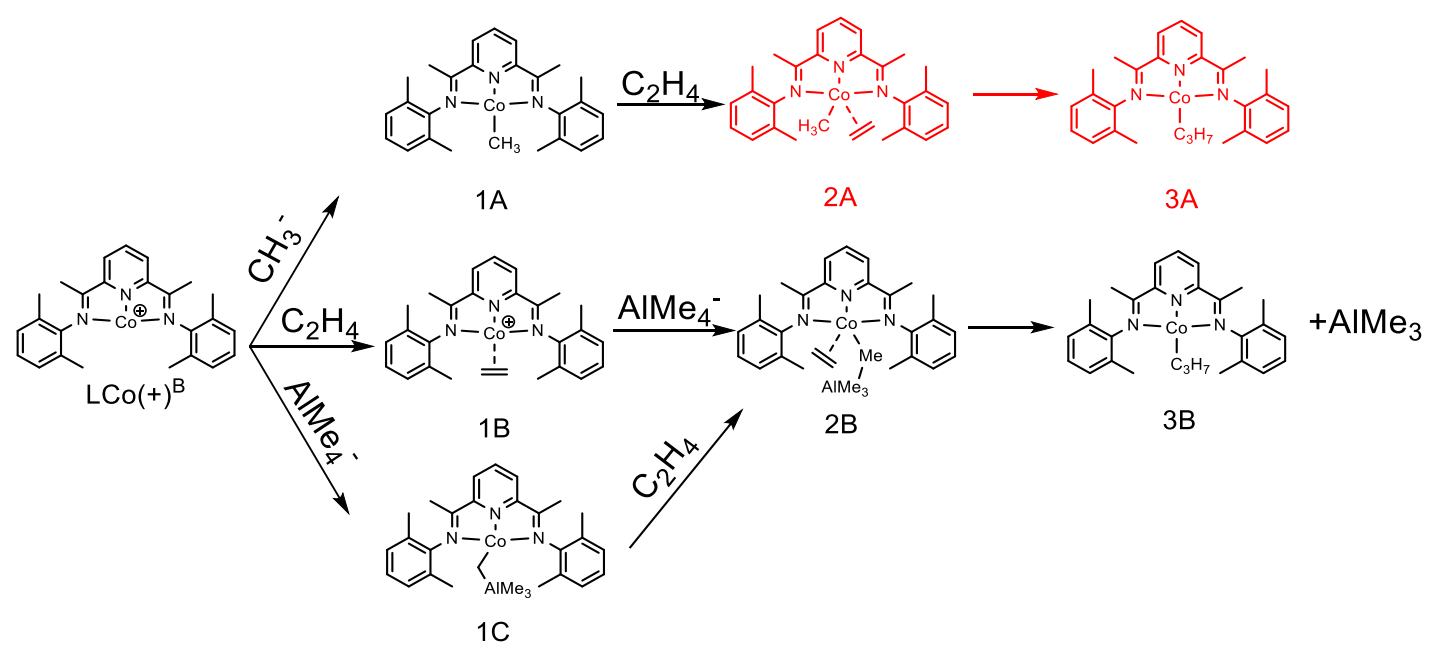

Scheme 5. The reaction pathway of ethylene polymerization catalyzed by $\mathbf{L}^{\mathrm{S}} \mathbf{C o}(+)^{\mathrm{B}}$ on addition of $\left[\mathrm{CH}_{3}\right]^{-}$or $\left[\mathrm{AlMe}_{4}\right]^{-}$or $\mathrm{C}_{2} \mathrm{H}_{4}$.

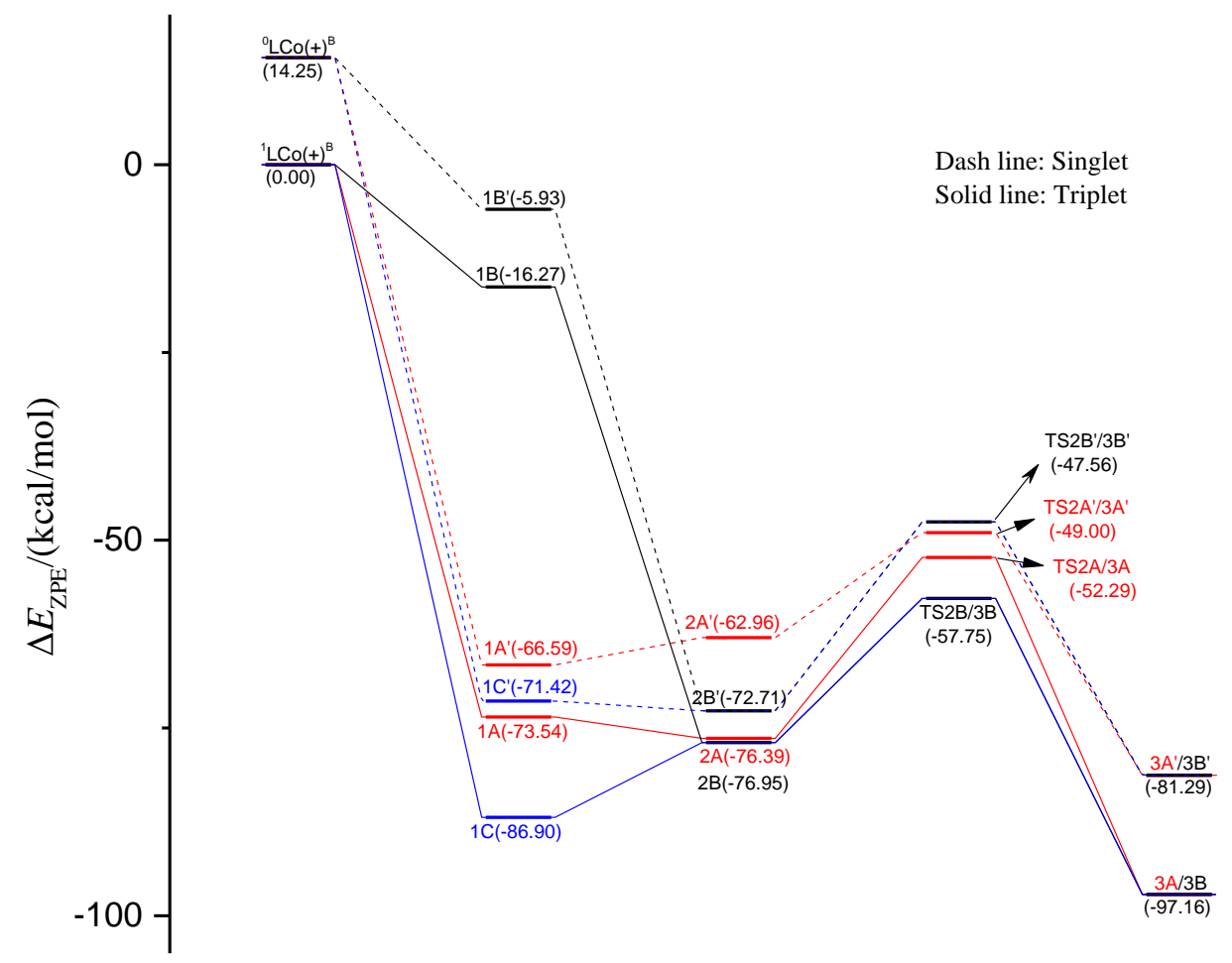

Figure 9. Comparison of the energy profiles for $\mathbf{L}^{\mathbf{S}} \mathbf{C o}(+)^{\mathbf{B}}\left(\mathrm{L}={ }^{\mathrm{Ar}} \mathrm{PDI}, \mathrm{s}\right.$ means spin states, here is singlet and triplet, the $\mathrm{B}$ means the cobalt metal having no other coordination besides the $\mathrm{L}$ ) on addition of $\left[\mathrm{CH}_{3}\right]^{-}$or $\left[\mathrm{AlMe}_{4}\right]-$ or $\mathrm{C}_{2} \mathrm{H}_{4}$.

Table 2. The structure parameter $\Delta$ calculated for the species in Figure 9.

\begin{tabular}{cccccccccc}
\hline & ${ }^{\mathbf{0}} \mathbf{C o}(+)^{\mathbf{B}}$ & $\mathbf{1 A}$ & $\mathbf{1 B}$ & $\mathbf{1 C}$ & $\mathbf{2 A}$ & $\mathbf{2 B}$ & $\mathbf{T S 2 A} / 3 \mathbf{A}$ & TS2B/3B & 3A/3B \\
\hline Singlet & 0.15 & 0.1 & 0.158 & 0.114 & 0.085 & 0.084 & 0.061 & 0.077 & 0.095 \\
Triplet & 0.181 & 0.123 & 0.18 & 0.119 & 0.123 & 0.168 & 0.112 & 0.116 & 0.114 \\
\hline
\end{tabular}

\section{Computational Methods}

Density functional theory (DFT) calculation was performed using the Gaussian 09 software package [51]. The geometric structures of the relevant species were optimized in the gas phase with the hybrid B3LYP which was used to produce reasonable results by other researchers [43,52]. In the 
investigation performed by Busico et al. [53], the B3LYP demonstrated moderate accuracy among the 22 functionals on transition states energies, agostic interactions, reaction energies and $\pi$-coordination energies for transition metal catalysts. The standard 6-311G(d) basis set was used for nonmetal atoms, while the SDD was chosen for the metal atom [54]. Vibration frequencies were calculated to check that the reaction intermediates were all positive and the TSs had only one imaginary frequency. The zero-point energy changes $(\Delta E)$ were used to discuss the catalytic reaction process. Additionally, possible spin states were considered for all the investigated systems. Bruin et al [41] have confirmed that the inclusion of solvent or expansion of the wave function in a larger basis set did not affect the calculations performance in the gas phase. Then, in this theoretical calculation solvent effect was not considered. Intrinsic reaction coordinate (IRC) calculations $[55,56]$ were also performed to check a TS connects two appropriate local minima in some of the reaction paths. In addition, natural bond orbital (NBO) analysis $[46,49,57,58]$ was conducted on the optimized structures to acquire a further insight into the charge distributions of the system [59]. Some of the bond order was also analyzed by the Mayer bond order analysis by Multiwfn [46].

\section{Conclusions}

The reactivities and electronic structures of the neutral, cationic bis(imino)pyridyl iron and cobalt species were explored and compared in this work by DFT calculations. Different spin states were considered for the four species $\mathbf{C o}(+), \mathbf{C o}(0), \mathbf{F e}(+), \mathbf{F e}(0)$. The results revealed that for all the species, the rate-determining step is the first ethylene insertion. The neutral cobalt system $\mathbf{C o}(0)$ had the lowest reactivity as it possessed the most electrons. As for the spin states in $\mathrm{Co}(+), \mathrm{Fe}(\mathbf{0})$ and $\mathbf{F e}(+)$, the Ins I and Ins II processes prefer to take place in high spin states, but the BHT and BHE tend to occur along with spin crossover. Additionally, the spin crossover is almost throughout the $\mathbf{C o}(+)$ species. Overall, due to the low steric substituent in the investigated species here, the BHT or BHE is the kinetically favorable process in comparison with the Ins II, but they are always energetically unfavorable. The $\mathbf{C o}(0)$ and $\mathbf{F e}(+)$ tend to perform chain termination through $\mathbf{B H E}$, while $\mathbf{F e}(0)$ and Co(+) through BHT.

Additionally, the electron numbers are the same for $\mathbf{C o}(+)$ and $\mathbf{F e}(\mathbf{0})$, which is one electron less and better reactivity than the neutral Co(0). The unpaired electrons are located mainly on the cobalt metal center in $\mathbf{C o}(+)$ while they are on both of the iron metal center and the PDI ligand in $\mathbf{F e}(\mathbf{0})$. The more electrons in the cobalt metal center may explain the occurrence of more spin crossover in $\mathbf{C o}(+)$ system. Additionally the loss of one electron from the Co(0) to form the $\mathbf{C o}(+)$ is mainly from the PDI ligand instead of the cobalt metal, as is the same for $\mathbf{F e}(0)$ to $\mathbf{F e}(+)$.

Moreover, a special unsymmetrically NN coordination manner was found between the PDI ligand and the cobalt metal in the neutral cobalt species Co(0). This may result in $14 \mathrm{e}$ deficient center. Through this center, the good activity in some asymmetric structures of electron-rich cobalt in the experiments may be explained. Furthermore, a process involving [AlMe $]^{-}$was proposed to explain the experimentally observed $\mathbf{L C o}(+)^{\mathbf{B}}\left(\mathrm{C}_{2} \mathrm{H}_{4}\right)(\mathbf{1 B})$ which could be generated from the $\mathbf{L C o}(+)^{\mathbf{B}}$ with $14 \mathrm{e}$ deficient center by ethylene coordination. A special intermediate, $\mathrm{Co}(+) \mathrm{B}\left(\mathrm{C}_{2} \mathrm{H}_{4}\right)\left[\mathrm{AlMe}_{4}\right]^{-}$with $\mathrm{Co}$ in $+\mathrm{I}$ and absence of $\mathrm{Co}-\mathrm{C} \sigma$ bond, was obtained. In this intermediate, the interaction of the cobalt metal atom with the $\left[\mathrm{AlMe}_{4}\right]^{-}$was less strong than with the coordinated ethylene. The chain growth in the cobalt species may proceed by attacking the carbon atom of the binding $\mathrm{C}_{2} \mathrm{H}_{4}$ from the methyl group in $\left[\mathrm{AlMe}_{4}\right]^{-}$. These calculations results may provide fundamental information for understanding and designing the catalysts of ethylene polymerization. 
Supplementary Materials: The following are available online at http://www.mdpi.com/2073-4344/10/12/1396/s1, Figure S1 The DFT optimized structures of the neutral cobalt system ${ }^{\mathbf{0}} \mathbf{C o}(\mathbf{0})$ in Figure 1, Figure S2 The DFT optimized structures of the neutral cobalt system ${ }^{1} \mathbf{C o}(0)$ in Figure 1, Figure S3 The DFT optimized structures of the cationic cobalt system ${ }^{1 / 2} \mathbf{C o}(+)$ in Figure 3, Figure S4 The DFT optimized structures of the cationic cobalt system ${ }^{3 / 2} \mathbf{C o}(+)$ in Figure 3, Figure S5 The DFT optimized structures of the cationic iron system ${ }^{\mathbf{1}} \mathbf{F e}(+)$ in Figure 5 , Figure S6 The DFT optimized structures of the cationic iron system ${ }^{2} \mathbf{F e}(+)$ in Figure 5, Figure S7 The DFT optimized structures of the neutral iron system ${ }^{1 / 2} \mathbf{F e}(0)$ in Figure 6, Figure S8 The DFT optimized structures of the neutral iron system ${ }^{3 / 2} \mathbf{F e}(\mathbf{0})$ in Figure 6, Figure S9 The DFT optimized structures of the cobalt system ${ }^{0} \mathbf{L C o}(+)^{\mathbf{B}}$ in Figure 9, Figure S10 The DFT optimized structures of the cobalt system ${ }^{\mathbf{1}} \mathbf{L C o}(+)^{\mathbf{B}}$ in Figure 9, Table S1 The factors for calculating the structure parameter $\Delta$ in ${ }^{0} \mathbf{C o}(0)$, Table S2 The factors for calculating the structure parameter $\Delta$ in ${ }^{1} \mathbf{C o}(0)$, Table S3 The factors for calculating the structure parameter $\Delta$ in ${ }^{1 / 2} \mathbf{C o}(+)$, Table S4 The factors for calculating the structure parameter $\Delta$ in ${ }^{3 / 2} \mathrm{Co}(+)$, Table S5 The factors for calculating the structure parameter $\Delta$ in ${ }^{1} \mathrm{Fe}(+)$, Table S6 The factors for calculating the structure parameter $\Delta$ in ${ }^{2} \mathrm{Fe}(+)$, Table S7 The factors for calculating the structure parameter $\Delta$ in ${ }^{1 / 2} \mathbf{F e}(0)$, Table $S 8$ The factors for calculating the structure parameter $\Delta$ in ${ }^{3 / 2} \mathbf{F e}(0)$, Table S9 The NBO charge distribution for ${ }^{\mathbf{s}} \mathbf{M}(q)-\mathbf{1}$ and ${ }^{\mathbf{s}} \mathbf{M}(q)-2, \mathrm{M}$ includes iron and cobalt, s means the spin states and the q refers to the charge number, Table S10 The factors for calculating the structure parameter $\Delta$ in ${ }^{0} \mathbf{C o}(+)^{\mathbf{B}}$, Table S11 The factors for calculating the structure parameter $\Delta$ in ${ }^{1} \mathbf{C o}(+)^{\mathbf{B}}$.

Author Contributions: Data curation, Z.L.; Formal analysis, Z.L. and Y.M.; Funding acquisition, W.-H.S.; Investigation, Z.L.; Project administration, W.-H.S.; Supervision, Y.M.; Writing—original draft, Z.L.; Writing—review \& editing, Z.L., Y.M. and W.-H.S. All authors have read and agreed to publish this version of manuscript.

Funding: This work is supported by the National Natural Science Foundation of China (No. 21871275).

Conflicts of Interest: The authors declare no conflict of interest.

\section{References}

1. Small, B.L.; Brookhart, M.; Bennett, A.M.A. Highly active iron and cobalt catalysts for the polymerization of ethylene. J. Am. Chem. Soc. 1998, 120, 4049-4050. [CrossRef]

2. Britovsek, G.J.P.; Gibson, V.C.; Kimberley, B.S.; Maddox, P.J.; McTavish, S.J.; Solan, G.A.; White, A.J.P.; Williams, D.J. Novel olefin polymerization catalysts based on iron and cobalt. Chem. Commun. 1998, 849-850. [CrossRef]

3. Zhang, W.; Wang, S.; Du, S.; Guo, C.-Y.; Hao, X.; Sun, W.-H. 2-(1-(2,4-Bis((di(4-fluorophenyl)methyl)-6methylphenylimino)ethyl)-6-(1-(arylimino)ethyl)pyridylmetal (iron or cobalt) Complexes: Synthesis, Characterization, and Ethylene Polymerization Behavior. Macromol. Chem. Phys. 2014, 215, 1797-1809. [CrossRef]

4. Ahmed, S.; Yang, W.; Ma, Z.; Sun, W.-H. Catalytic Activities of Bis(pentamethylene)pyridyl(Fe/Co) Complex Analogues in Ethylene Polymerization by Modeling Method. J. Phys. Chem. A 2018, 122, 9637-9644. [CrossRef] [PubMed]

5. Huang, C.; Zakharov, V.A.; Semikolenova, N.V.; Matsko, M.A.; Solan, G.A.; Sun, W.-H. A comparative kinetic study of ethylene polymerization mediated by iron, cobalt and chromium catalysts bearing the same N,N,N-bis(imino)trihydroquinoline. J. Catal. 2019, 369, 1-9. [CrossRef]

6. Wang, Z.; Solan, G.A.; Zhang, W.; Sun, W.-H. Carbocyclic-fused N,N,N-pincer ligands as ring-strain adjustable supports for iron and cobalt catalysts in ethylene oligo-/polymerization. Coord. Chem. Rev. 2018, 363, 92-108. [CrossRef]

7. Phillips, A.M.F.; Suo, H.; Guedes da Silva, M.d.F.C.; Pombeiro, A.J.L.; Sun, W.-H. Recent developments in vanadium-catalyzed olefin coordination polymerization. Coord. Chem. Rev. 2020, 416, 213332. [CrossRef]

8. Bariashir, C.; Huang, C.; Solan, G.A.; Sun, W.-H. Recent advances in homogeneous chromium catalyst design for ethylene tri-, tetra-, oligo- and polymerization. Coord. Chem. Rev. 2019, 385, 208-229. [CrossRef]

9. Suo, H.; Solan, G.A.; Ma, Y.; Sun, W.-H. Developments in compartmentalized bimetallic transition metal ethylene polymerization catalysts. Coord. Chem. Rev. 2018, 372, 101-116. [CrossRef]

10. Chirik, P.J. Carbon-Carbon Bond Formation in a Weak Ligand Field: Leveraging Open-Shell First-Row Transition-Metal Catalysts. Angew. Chem. Int. Ed. 2017, 56, 5170-5181. [CrossRef]

11. Zhang, W.; Chai, W.; Sun, W.-H.; Hu, X.; Redshaw, C.; Hao, X. 2-(1-(Arylimino)ethyl)-8-arylimino5,6,7-trihydroquinoline Iron(II) Chloride Complexes: Synthesis, Characterization, and Ethylene Polymerization Behavior. Organometallics 2012, 31, 5039-5048. [CrossRef] 
12. Huang, F.; Xing, Q.; Liang, T.; Flisak, Z.; Ye, B.; Hu, X.; Yang, W.; Sun, W.-H. 2-(1-Aryliminoethyl)-9-arylimino5,6,7,8-tetrahydrocycloheptapyridyl iron(II) dichloride: Synthesis, characterization, and the highly active and tunable active species in ethylene polymerization. Dalton Trans. 2014, 43, 16818-16829. [CrossRef] [PubMed]

13. Sun, W.-H.; Kong, S.; Chai, W.; Shiono, T.; Redshaw, C.; Hu, X.; Guo, C.; Hao, X. 2-(1-(Arylimino)ethyl)-8arylimino-5,6,7-trihydroquinolylcobalt dichloride: Synthesis and polyethylene wax formation. Appl. Catal. A 2012, 447-448, 67-73. [CrossRef]

14. Huang, F.; Zhang, W.; Sun, Y.; Hu, X.; Solan, G.A.; Sun, W.-H. Thermally stable and highly active cobalt precatalysts for vinyl-polyethylenes with narrow polydispersities: Integrating fused-ring and imino-carbon protection into ligand design. New J. Chem. 2016, 40, 8012-8023. [CrossRef]

15. Zhang, Y.; Suo, H.; Huang, F.; Liang, T.; Hu, X.; Sun, W.-H. Thermo-stable 2-(arylimino)benzylidene9-arylimino-5,6,7,8-tetrahydro cyclohepta[b]pyridyliron(II) precatalysts toward ethylene polymerization and highly linear polyethylenes. J. Polym. Sci. Part A Polym. Chem. 2017, 55, 830-842. [CrossRef]

16. Appukuttan, V.K.; Liu, Y.; Son, B.C.; Ha, C.-S.; Suh, H.; Kim, I. Iron and Cobalt Complexes of 2,3,7,8-Tetrahydroacridine-4,5(1H,6H)-diimine Sterically Modulated by Substituted Aryl Rings for the Selective Oligomerization to Polymerization of Ethylene. Organometallics 2011, 30, 2285-2294. [CrossRef]

17. Du, S.; Wang, X.; Zhang, W.; Flisak, Z.; Sun, Y.; Sun, W.-H. A practical ethylene polymerization for vinyl-polyethylenes: Synthesis, characterization and catalytic behavior of $\alpha, \alpha^{\prime}$-bisimino-2,3:5,6-bis (pentamethylene)pyridyliron chlorides. Polym. Chem. 2016, 7, 4188-4197. [CrossRef]

18. Zada, M.; Guo, L.; Ma, Y.; Zhang, W.; Flisak, Z.; Sun, Y.; Sun, W.-H. Activity and Thermal Stability of Cobalt(II)-Based Olefin Polymerization Catalysts Adorned with Sterically Hindered Dibenzocycloheptyl Groups. Molecules 2019, 24, 2007. [CrossRef]

19. Wang, Z.; Ma, Y.; Guo, J.; Liu, Q.; Solan, G.A.; Liang, T.; Sun, W.-H. Bis(imino)pyridines fused with 6- and 7-membered carbocylic rings as N,N,N-scaffolds for cobalt ethylene polymerization catalysts. Dalton Trans. 2019, 48, 2582-2591. [CrossRef]

20. Guo, L.; Zada, M.; Zhang, W.; Vignesh, A.; Zhu, D.; Ma, Y.; Liang, T.; Sun, W.-H. Highly linear polyethylenes tailored with 2,6-bis[1-(p-dibenzo-cycloheptylarylimino)ethyl]pyridylcobalt dichlorides. Dalton Trans. 2019, 48, 5604-5613. [CrossRef]

21. Chen, Q.; Zhang, W.; Solan, G.A.; Zhang, R.; Guo, L.; Hao, X.; Sun, W.-H. CH(phenol)-Bridged Bis(imino)pyridines as Compartmental Supports for Diiron Precatalysts for Ethylene Polymerization: Exploring Cooperative Effects on Performance. Organometallics 2018, 37, 4002-4014. [CrossRef]

22. Chen, Q.; Zhang, W.; Solan, G.A.; Liang, T.; Sun, W.-H. Methylene-bridged bimetallic bis(imino)pyridinecobaltous chlorides as precatalysts for vinyl-terminated polyethylene waxes. Dalton Trans. 2018, 47, 6124-6133. [CrossRef] [PubMed]

23. Khoshsefat, M.; Dechal, A.; Ahmadjo, S.; Mortazavi, S.M.M.; Zohuri, G.; Soares, J.B.P. Amorphous to high crystalline PE made by mono and dinuclear Fe-based catalysts. Eur. Polym. J. 2019, 119, 229-238. [CrossRef]

24. Huang, F.; Zhang, W.; Yue, E.; Liang, T.; Hu, X.; Sun, W.-H. Controlling the molecular weights of polyethylene waxes using the highly active precatalysts of 2-(1-aryliminoethyl)-9-arylimino-5,6,7,8tetrahydrocycloheptapyridylcobalt chlorides: Synthesis, characterization, and catalytic behavior. Dalton Trans. 2016, 45, 657-666. [CrossRef] [PubMed]

25. Du, S.; Zhang, W.; Yue, E.; Huang, F.; Liang, T.; Sun, W.-H. $\alpha, \alpha^{\prime}$-Bis(arylimino)-2,3:5,6-bis (pentamethylene)pyridylcobalt Chlorides: Synthesis, Characterization, and Ethylene Polymerization Behavior. Eur. J. Inorg. Chem. 2016, 2016, 1748-1755. [CrossRef]

26. Britovsek, G.J.P.; Clentsmith, G.K.B.; Gibson, V.C.; Goodgame, D.M.L.; McTavish, S.J.; Pankhurst, Q.A. The nature of the active site in bis(imino)pyridine iron ethylene polymerisation catalysts. Catal. Commun. 2002, 3, 207-211. [CrossRef]

27. Humphries, M.J.; Tellmann, K.P.; Gibson, V.C.; White, A.J.P.; Williams, D.J. Investigations into the mechanism of activation and initiation of ethylene polymerization by bis(imino)pyridine cobalt catalysts: Synthesis, structures, and deuterium labeling studies. Organometallics 2005, 24, 2039-2050. [CrossRef]

28. Gibson, V.C.; Humphries, M.J.; Tellmann, K.P.; Wass, D.F.; White, A.J.; Williams, D.J. The nature of the active species in bis(imino)pyridyl cobalt ethylene polymerisation catalysts. Chem. Commun. 2001, 2252-2253. [CrossRef]

29. Roemelt, C.; Weyhermueller, T.; Wieghardt, K. Structural characteristics of redox-active pyridine-1,6-diimine complexes: Electronic structures and ligand oxidation levels. Coord. Chem. Rev. 2019, 380, 287-317. [CrossRef] 
30. Bryliakov, K.P.; Semikolenova, N.V.; Zakharov, V.A.; Talsi, E.P. Active intermediates of ethylene polymerization over 2,6-bis(imino)pyridyl iron complex activated with aluminum trialkyls and methylaluminoxane. Organometallics 2004, 23, 5375-5378. [CrossRef]

31. Bryliakov, K.P.; Talsi, E.P.; Semikolenova, N.V.; Zakharov, V.A. Formation and Nature of the Active Sites in Bis(imino)pyridine Iron-Based Polymerization Catalysts. Organometallics 2009, 28, 3225-3232. [CrossRef]

32. Bryliakov, K.P.; Talsi, E.P. Frontiers of mechanistic studies of coordination polymerization and oligomerization of $\alpha$-olefins. Coord. Chem. Rev. 2012, 256, 2994-3007. [CrossRef]

33. Kleigrewe, N.; Steffen, W.; Blomker, T.; Kehr, G.; Frohlich, R.; Wibbeling, B.; Erker, G.; Wasilke, J.C.; $\mathrm{Wu}$, G.; Bazan, G.C. Chelate bis(imino)pyridine cobalt complexes: Synthesis, reduction, and evidence for the generation of ethene polymerization catalysts by $\mathrm{Li}+$ cation activation. J. Am. Chem. Soc. 2005, 127, 13955-13968. [CrossRef] [PubMed]

34. Soshnikov, I.E.; Semikolenova, N.V.; Bushmelev, A.N.; Bryliakov, K.P.; Lyakin, O.V.; Redshaw, C.; Zakharov, V.A.; Talsi, E.P. Investigating the Nature of the Active Species in Bis(imino)pyridine Cobalt Ethylene Polymerization Catalysts. Organometallics 2009, 28, 6003-6013. [CrossRef]

35. Deng, L.Q.; Margl, P.; Ziegler, T. Mechanistic aspects of ethylene polymerization by iron(II)-bisimine pyridine catalysts: A combined density functional theory and molecular mechanics study. J. Am. Chem. Soc. 1999, 121, 6479-6487. [CrossRef]

36. Kwon, D.H.; Small, B.L.; Sydora, O.L.; Bischof, S.M.; Ess, D.H. Challenge of Using Practical DFT to Model Fe Pendant Donor Diimine Catalyzed Ethylene Oligomerization. J. Phys. Chem. C 2019, 123, 3727-3739. [CrossRef]

37. Cruz, V.L.; Ramos, J.; Martinez-Salazar, J.; Gutierrez-Oliva, S.; Toro-Labbe, A. Theoretical Study on a Multicenter Model Based on Different Metal Oxidation States for the Bis(imino)pyridine Iron Catalysts in Ethylene Polymerization. Organometallics 2009, 28, 5889-5895. [CrossRef]

38. Griffiths, E.A.H.; Britovsek, G.J.P.; Gibson, V.C.; Gould, I.R. Highly active ethylene polymerisation catalysts based on iron: An ab initio study. Chem. Commun. 1999, 1333-1334. [CrossRef]

39. Tondreau, A.M.; Milsmann, C.; Patrick, A.D.; Hoyt, H.M.; Lobkovsky, E.; Wieghardt, K.; Chirik, P.J. Synthesis and Electronic Structure of Cationic, Neutral, and Anionic Bis(imino)pyridine Iron Alkyl Complexes: Evaluation of Redox Activity in Single-Component Ethylene Polymerization Catalysts. J. Am. Chem. Soc. 2010, 132, 15046-15059. [CrossRef]

40. Khoroshun, D.V.; Musaev, D.G.; Vreven, T.; Morokuma, K. Theoretical study on bis(imino)pyridyl-Fe(II) olefin poly- and oligomerization catalysts. Dominance of different spin states in propagation and beta-hydride transfer pathways. Organometallics 2001, 20, 2007-2026. [CrossRef]

41. Boudene, Z.; Boudier, A.; Breuil, P.-A.R.; Olivier-Bourbigou, H.; Raybaud, P.; Toulhoat, H.; de Bruin, T. Understanding the role of aluminum-based activators in single site iron catalysts for ethylene oligomerization. J. Catal. 2014, 317, 153-157. [CrossRef]

42. Bouwkamp, M.W.; Bart, S.C.; Hawrelak, E.J.; Trovitch, R.J.; Lobkovsky, E.; Chirik, P.J. Square planar bis(imino)pyridine iron halide and alkyl complexes. Chem. Commun. 2005, 3406-3408. [CrossRef] [PubMed]

43. Bellows, S.M.; Cundari, T.R.; Holland, P.L. Spin Crossover during $\beta$-Hydride Elimination in High-Spin Iron(II)- and Cobalt(II)-Alkyl Complexes. Organometallics 2013, 32, 4741-4751. [CrossRef]

44. Huang, C.; Huang, Y.; Ma, Y.; Solan, G.A.; Sun, Y.; Hu, X.; Sun, W.-H. Cycloheptyl-fused N,N,N'-chromium catalysts with selectivity for vinyl-terminated polyethylene waxes: Thermal optimization and polymer functionalization. Dalton Trans. 2018, 47, 13487-13497. [CrossRef]

45. Bouwkamp, M.W.; Lobkovsky, E.; Chirik, P.J. Bis(imino)pyridine iron(II) alkyl cations for olefin polymerization. J. Am. Chem. Soc. 2005, 127, 9660-9661. [CrossRef] [PubMed]

46. Lu, T.; Chen, F.W. Multiwfn: A multifunctional wavefunction analyzer. J. Comput. Chem. 2012, 33, 580-592. [CrossRef]

47. Raucoules, R.; de Bruin, T.; Raybaud, P.; Adamo, C. Theoretical Unraveling of Selective 1-Butene Oligomerization Catalyzed by Iron-Bis(arylimino)pyridine. Organometallics 2009, 28, 5358-5367. [CrossRef]

48. Reed, A.E.; Weinstock, R.B.; Weinhold, F. Natural population analysis. J. Chem. Phys. 1985, 83, 735-746. [CrossRef]

49. Ba, J.; Du, S.; Yue, E.; Hu, X.; Flisak, Z.; Sun, W.-H. Constrained formation of 2-(1-(arylimino)ethyl)-7-arylimino6,6-dimethylcyclopentapyridines and their cobalt(ii) chloride complexes: Synthesis, characterization and ethylene polymerization. RSC Adv. 2015, 5, 32720-32729. [CrossRef]

50. Pasha, F.A.; Basset, J.-M.; Toulhoat, H.; de Bruin, T. DFT Study on the Impact of the Methylaluminoxane Cocatalyst in Ethylene Oligomerization Using a Titanium-Based Catalyst. Organometallics 2015, 34, 426-431. [CrossRef] 
51. Frisch, M.J.; Trucks, G.W.; Schlegel, H.B.; Scuseria, G.E.; Robb, M.A.; Cheeseman, J.R.; Scalmani, G.; Barone, V.; Mennucci, B.; Petersson, G.A.; et al. Gaussian 09, Revision E.01; Gaussian, Inc.: Wallingford, CT, USA, 2013.

52. Minaev, B.; Baryshnikova, A.; Sun, W.-H. Spin-dependent effects in ethylene polymerization with bis(imino)pyridine iron(II) complexes. J. Organomet. Chem. 2016, 811, 48-65. [CrossRef]

53. Ehm, C.; Budzelaar, P.H.M.; Busico, V. Calculating accurate barriers for olefin insertion and related reactions. J. Organomet. Chem. 2015, 775, 39-49. [CrossRef]

54. Dolg, M.; Wedig, U.; Stoll, H.; Preuss, H. Energy-adjusted abinitio pseudopotentials for the 1st-row transition-elements. J. Chem. Phys. 1987, 86, 866-872. [CrossRef]

55. Grimme, S.; Antony, J.; Ehrlich, S.; Krieg, H. A consistent and accurate ab initio parametrization of density functional dispersion correction (DFT-D) for the 94 elements H-Pu. J. Chem. Phys. 2010, 132, 154104. [CrossRef] [PubMed]

56. Gonzalez, C.; Schlegel, H.B. Reaction-path following in mass-weighted internal coordinates. J. Phys. Chem. 1990, 94, 5523-5527. [CrossRef]

57. Reed, A.E.; Weinhold, F. Natural localized molecular-orbitals. J. Chem. Phys. 1985, 83, 1736-1740. [CrossRef]

58. Reed, A.E.; Curtiss, L.A.; Weinhold, F. Intermolecular interactions from a natural bond orbital, donor-acceptor viewpoint. Chem. Rev. 1988, 88, 899-926. [CrossRef]

59. Reed, A.E.; Schleyer, P.V. chemical bonding in hypervalent molecules-The dominance of ionic bonding and negative hyperconjugation over d-orbital participation. J. Am. Chem. Soc. 1990, 112, 1434-1445. [CrossRef]

Publisher's Note: MDPI stays neutral with regard to jurisdictional claims in published maps and institutional affiliations. 